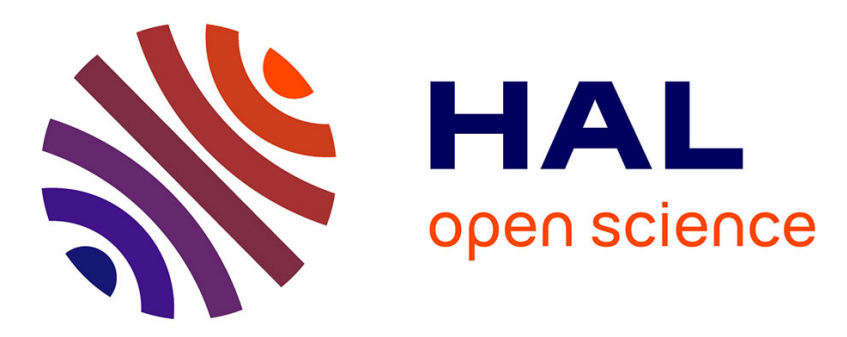

\title{
SDR enzymes oxidize specific lipidic alkynylcarbinols into cytotoxic protein-reactive species
}

Pascal Demange, Etienne Joly, Julien Marcoux, Patrick Zanon, Dymytrii Listunov, Pauline Rullière, Cécile Barthes, Céline Noirot, Jean-Baptiste Izquierdo, Karen Pradines, et al.

\section{To cite this version:}

Pascal Demange, Etienne Joly, Julien Marcoux, Patrick Zanon, Dymytrii Listunov, et al.. SDR enzymes oxidize specific lipidic alkynylcarbinols into cytotoxic protein-reactive species. 2021. hal03371218

\author{
HAL Id: hal-03371218 \\ https://hal.science/hal-03371218
}

Preprint submitted on 11 Oct 2021

HAL is a multi-disciplinary open access archive for the deposit and dissemination of scientific research documents, whether they are published or not. The documents may come from teaching and research institutions in France or abroad, or from public or private research centers.
L'archive ouverte pluridisciplinaire $\mathbf{H A L}$, est destinée au dépôt et à la diffusion de documents scientifiques de niveau recherche, publiés ou non, émanant des établissements d'enseignement et de recherche français ou étrangers, des laboratoires publics ou privés.

\section{(1) (1) $\$$}

Distributed under a Creative Commons Attribution - NonCommercial - NoDerivatives| 4.0 


\section{SDR enzymes oxidize specific lipidic alkynylcarbinols into cytotoxic}

\section{2 protein-reactive species}

3 Pascal Demange ${ }^{1, \mathbb{a}}$, Etienne Joly ${ }^{1, \mathrm{a}}$, Julien Marcoux ${ }^{1, \mathrm{a}}$, Patrick R. A. Zanon ${ }^{2}$, Dymytrii Listunov ${ }^{3,4}$,

4 Pauline Rullière ${ }^{3}$, Cécile Barthes ${ }^{4}$, Céline Noirot $^{5}$, Jean-Baptiste Izquierdo ${ }^{1}$, Karen Pradines ${ }^{1,6}$,

5 Romain $\mathrm{Hee}^{1,6}$, Maria Vieira de Brito ${ }^{4,7}$, Marlène Marcellin ${ }^{1}$, Rémi-Félix Serre ${ }^{8}$, Olivier Bouchez ${ }^{8}$,

6 Odile Burlet-Schiltz ${ }^{1}$, Maria Conceição Ferreira Oliveira ${ }^{7}$, Stéphanie Ballereau ${ }^{3}$, Vania Bernardes-

7 Génisson ${ }^{4}$, Valérie Maraval ${ }^{4}$, Patrick Calsou ${ }^{1,2}$, Stephan M. Hacker ${ }^{2}$, Yves Génisson ${ }^{3, t, *}$, Remi

8 Chauvin ${ }^{4, t, *}$, Sébastien Britton ${ }^{1,6, *}$

$9 \quad{ }^{*}$ corresponding authors. $\quad{ }^{a}, \dagger$ equal contribution.

10 AFFILIATIONS:

111 Institut de Pharmacologie et de Biologie Structurale, IPBS, Université de Toulouse, CNRS, UPS,

12 Toulouse, France.

132 Department of Chemistry, Technical University of Munich, Lichtenbergstrasse 4, 85748

14 Garching, Germany

153 LSPCMIB, UMR5068, CNRS, Université de Toulouse, UPS, 118 route de Narbonne, 31062

16 Toulouse, France.

174 LCC-CNRS, Université de Toulouse, CNRS, UPS, Toulouse, France.

185 INRAE, UR 875 Unité de Mathématique et Informatique Appliquées, Genotoul Bioinfo, Auzeville,

19 CS 52627, 31326, Castanet-Tolosan, France.

206 Equipe labellisée la Ligue contre le Cancer 2018.

217 Department of Organic and Inorganic Chemistry, Science Center, Federal University of Ceará,

22 Fortaleza-CE, 60455-970, Brazil. 


\section{ABSTRACT:}

Hundreds of cytotoxic natural or synthetic lipidic compounds contain chiral alkynylcarbinol motifs, but the mechanism of action of those potential therapeutic agents remains unknown. Using a genetic screen in haploid human cells, we discovered that the enantiospecific cytotoxicity of numerous terminal alkynylcarbinols, including the highly cytotoxic dialkynylcarbinols, involves a bioactivation by HSD17B11, a short-chain dehydrogenase/reductase (SDR) known to oxidize the C-17 carbinol center of androstan3-alpha,17-beta-diol to the corresponding ketone. A similar oxidation of dialkynylcarbinols generates dialkynylketones, that we characterize as highly protein-reactive electrophiles. We established that, once bioactivated in cells, the dialkynylcarbinols covalently modify several proteins involved in protein-quality control mechanisms, resulting in their lipoxidation on cysteines and lysines through Michael addition. For some proteins, this triggers their association to cellular membranes and results in endoplasmic reticulum stress, unfolded protein response activation, ubiquitin-proteasome system inhibition and cell death by apoptosis. Finally, as a proof-of-concept, we show that generic lipidic alkynylcarbinols can be devised to be bioactivated by other SDRs, including human RDH11 and HPGD/15-PGDH. Given that the SDR superfamily is one of the largest and most ubiquitous, this unique cytotoxic mechanism-of-action could be widely exploited to treat diseases, in particular cancer, through the design of tailored prodrugs. 


\section{MAIN TEXT}

\section{Introduction}

Nature is a rich source of bioactive compounds, some of which can be directly exploited to treat diseases. Some of them reveal sophisticated mechanisms of action which can be mimicked by designing synthetic molecules with specific features (1). Marine sponges have attracted pharmaceutical interest since the discovery in the 1950s of C-nucleosides in Cryptotethia crypta that led to the development of cytosine arabinoside (ara-C or cytarabine) and analogues as anticancer treatments for acute myelogenous leukemia $(2,3)$. In a different structural series, several cytotoxic acetylenic lipids bearing a terminal alkenylalkynylcarbinol (AAC) pharmacophore have since been isolated from marine sponges, such as petrocortyne A (Supplementary Figure 1), isolated from Petrosia sp. (4) and fulvinol isolated from Haliclona fulva (5). The simplest cytotoxic AAC representative, (S)-eicos-(4E)-en-1-yn-3-ol ((S)-1, Supplementary Figure 1), was isolated from the marine sponge Cribrochalina vasculum (6). It demonstrated high cytotoxic activity selectively towards non-small cell lung carcinoma cells as compared to normal lung fibroblasts (7). Starting from (S)-1, an extensive structure-activity relationship study in human cancer cell lines established that (Supplementary Figure 1): i) the non-natural enantiomer $(R)-1$ has higher cytotoxic activity, ii) homologues with shorter lipidic tails are more cytotoxic, with an optimum total aliphatic backbone of 17 carbon atoms (e.g. (R)-2), and iii) replacement of the internal $\mathrm{C}=\mathrm{C}$ bond by $\mathrm{a} \mathrm{C} \equiv \mathrm{C}$ bond, giving rise to a terminal dialkynylcarbinol (DAC) pharmacophore, further increases cytotoxicity, to reach an IC $\mathrm{C}_{50}$ down to $90 \mathrm{nM}$ for the DAC (S)-3 (8-10). However, despite this significant level of activity, the mode of action of this family of molecules, including the natural compound (S)-1, remains elusive (7).

Here we use functional genomics and chemoproteomics to decipher how cytotoxic DACs and related molecules mediate their biological effect. We discover that they behave as prodrugs enantiospecifically bioactivated by a member of the Short-chain Dehydrogenase/Reductase 
(SDR) family. Finally, we design new SDR-bioactivated DACs derivatives, establishing this family of lipidic alkynylcarbinols as a large and untapped reservoir of cytotoxic prodrugs.

\section{Results}

The SDR HSD17B11 governs (S)-DACs cytotoxicity. To determine how cytotoxic DACs mediate their effect on human cells, we applied a genetic approach using the pseudo-haploid human cell line HAP-1 (11). Given that (S)-3 had the greatest cytotoxic activity of all the DACs previously tested (8-10), we screened for mutations that could render HAP-1 cells resistant to (S)3. We first confirmed in HAP-1 that (S)-3, but not (R)-3 (Figure 1A), exhibits nanomolar cytotoxic activity (Figure 1B, IC $5062.4 \mathrm{nM}$ ), in agreement with previous results on HCT116 colon cancer cells (8). We used Ethyl-Methane Sulfonate (EMS) to generate a mutagenized HAP-1 population and selected resistant clones using a lethal $250 \mathrm{nM}(S)-3$ concentration. Ten individual (S)-3resistant clones (DACR) were isolated, displaying a 38- to 62-fold resistance to (S)-3 (Figure 1C) but similar sensitivity as parental cells to two unrelated compounds, bortezomib and doxorubicin (Supplementary Figure 2A,B). Based on previous work $(12,13)$, and considering that EMS induces mainly point mutations under these conditions (14), we selected four DACR clones for RNA-seq analysis, to identify mis- or non-sense mutations accounting for the resistance. Around nine mutated genes were identified per clone (Supplementary Figure 2C), with KCTD5 and HSD17B11 being the only mutated genes shared by more than two clones (Supplementary Figure 2D). KCTD5 encodes for an E3-ubiquitin ligase substrate adaptor identified in a genetic screen as a negative regulator of the Akt pathway (15). However, while KCTD5 mRNA was expressed in all DACR clones, HSD17B11 mRNA levels were strongly reduced in the only clone without HSD17B11 coding mutations (\#A5, Supplementary Figure 2E). This suggested that mutations or lack of expression of HSD17B11 were responsible for DACR clone resistance. To confirm this, we sequenced HSD17B11 cDNAs from six other DACR clones, and detected non- 
synonymous HSD17B11 mutations in five, and no HSD17B11 cDNA in the sixth, suggesting loss of expression (Figure 1D,E). These data strongly supported a role for HSD17B11 in mediating (S)-3 cytotoxicity.

HSD17B11 encodes for the estradiol 17-beta-dehydrogenase 11, a member of the SDR superfamily. HSD17B11, also called SDR16C2, PAN1B, DHRS8 or retSDR2, localizes to the endoplasmic reticulum (ER) and lipid droplets (LD) via a N-terminal targeting domain (Figure 1E), where it uses NAD+ to catalyze oxidation of the C17 carbinol center of androstan-3-alpha,17-betadiol to generate androsterone $(16,17)$ (see Figure 2A). The HSD17B11 protein was barely detectable in all the DACR clones (Figure 1F, lower band), suggesting that the mutations result in protein instability. Using the DACR\#A5 clone, in which HSD17B11 RNA was strongly downregulated ( 200 fold, Supplementary Figure 2E), we performed complementation experiments with plasmids coding for GFP alone, or wild-type (WT) or S172L HSD17B11-GFP. This mutation was selected because the $S 172$ residue is critical for catalysis (18), and the DACR\#A4 clone, which carried S172L mutations, was the only one in which traces of full length HSD17B11 could be detected (Figure 1F). Complemented DACR\#A5 cells stably expressing WT and S172L HSD17B11-GFP at similar levels were successfully isolated (Figure 1G), and (S)-3 was $\sim 50$ times more active against cells expressing WT HSD17B11 compared to control GFP-complemented cells or cells expressing S172L HSD17B11 (Figure 1H). This supports that HSD17B11 catalytic activity is critical for (S)-DAC cytotoxicity. Notably, the DACR\#A4 clone (S172L mutation) was also resistant to six other cytotoxic AACs: the naturally occurring AAC (S)-1 (Supplementary Figure 3A), its synthetic enantiomer $(R)-1$, its shorter homologue $(R)-2$, the synthetic AAC (S)-4 with an internal $\mathrm{C} \equiv \mathrm{C}$ bond and an external $\mathrm{C}=\mathrm{C}$ bond (Supplementary Figure 3B), the allenylalkynylcarbinol (AllAC) $\left(R, S_{\mathrm{a}}\right)-5$ (19) and the more cytotoxic butadiynylalkynylcarbinol (BAC) (S)-6 (20) (Supplementary Figure 3C). Thus, HSD17B11 functionality governs the enantiospecific cytotoxicity of the natural compound (S)-1 but also of all the more cytotoxic 
synthetic derivatives tested. In addition, HSD17B11 has been recently identified as mediating, through an unknown mechanism, the cytotoxic effect of dehydrofalcarinol, a polyacetylenic compound with a terminal butadiynylalkenylcarbinol motif isolated from several plants of the Asteraceae family (21).

We next tested the cytotoxic activity of (S)-3 on a panel of 15 cancer cell lines. This revealed that the osteosarcoma U2OS cell line was the most sensitive to (S)-3 while the breast cancer cell line T47D was highly resistant (Supplementary Figure 4A). In agreement, HSD17B11 protein was undetectable in T47D, while U2OS displayed the highest levels (Supplementary Figure 4B), in agreement with reported mRNA levels (The Cancer Cell Line Encyclopedia dataset (22)). In addition, (S)-3 was particularly cytotoxic toward four other osteosarcoma cell lines as compared to normal cell lines or primary osteoblasts (Supplementary Figure 4C), suggesting that DACs could prove useful to treat this type of cancer. CRISPR/Cas9-mediated inactivation of HSD17B11 also conferred significant (S)-3 resistance to U2OS cells, which was suppressed by wild-type HSD17B11-GFP but not by the S172L mutant or GFP alone (Supplementary Figure 5A,B). This was further confirmed using two different small-interfering RNAs (siRNA) to down-regulate HSD17B11 in U2OS (Supplementary Figure 5C,D) and in the non-small cell lung carcinoma cell line A549, in which CRISPR/Cas9-mediated HSD17B11 inactivation also conferred (S)-3 resistance (Supplementary Figure 5E,F). Altogether, these data establish that HSD17B11 is critical in multiple cell lines for (S)-3 cytotoxic activity, and suggest that (S)-3 behaves as an HSD17B11-bioactivated prodrug. In addition, the acute toxicity of (S)-3 towards osteosarcoma cell lines indicates that DACs could be developed into a targeted anti-cancer therapy.

Dialkynylketones are protein-reactive species. We next investigated the downstream mechanism of cytotoxic action of the DAC (S)-3. The C17 carbinol center of androstan-3-alpha,17beta-diol, which is naturally oxidized by HSD17B11 (Figure 2A (16)), has the same spatial orientation as the (S)-3 carbinol when its lipidic chain is superimposed with the $C 13(C 18)$ side of 
the steroid skeleton (Figure 2B). This suggested that HSD17B11 enantiospecifically recognizes and oxidizes (S)-3 into a "dialkynylketone" 7 (DACone), a diynone that could be the cytotoxic species. However, when the DACone 7 was previously synthesized and tested, no cytotoxic activity was found (9). Given the high in vitro electrophilic reactivity of ynones as Michael acceptors of thiols and amines (23), we considered that medium components such as serum albumin may rapidly react with and inactivate DACones. To test this, we synthesized the DACone 7 , as well as a homologue with a shorter alkyl chain $\mathbf{8}$, and treated U2OS cells in a protein-free medium (PBS containing $\mathrm{CaCl}_{2}$ and $\mathrm{MgCl}_{2}$ to maintain cellular adhesion). Both the DACones 7 and 8 were indeed cytotoxic in the absence of serum, with 8 (short chain) being even more active than (S)-3 (Figure 2C). While the cytotoxicity of (S)-3 was strongly reduced by inactivation of HSD17B11, the cytotoxicity of the DACones $\mathbf{7}$ and $\mathbf{8}$ was not affected, supporting the notion that the DACones are the cytotoxic products generated from DACs by HSD17B11.

To further analyze the interaction between DACones and proteins, we used copper-mediated azide-alkyne cycloaddition (CuAAC "click chemistry"), which can be used to monitor what happens to drugs in various biological environments, including inside cells $(24,25)$. We synthesized "clickable" analogues, i.e. bearing a terminal $\mathrm{C} \equiv \mathrm{CH}$ tag, for each DAC enantiomer $((S)-\mathbf{9}$ and $(R)$ 9), and for long and short DACones (10 and 11, Figure 2B), and used them to monitor the formation of covalent bonds between DACones and serum proteins. The clickable DACone 10, or clickable DAC (S)-9 as control, were incubated with fetal bovine serum (FBS) or purified bovine serum albumin (BSA), followed by CuAAC-mediated ligation of an AlexaFluor647-azido fluorophore to the free $\mathrm{C} \equiv \mathrm{CH}$ tag. The proteins were separated by SDS-PAGE and scanned for fluorescence (26). Covalent adducts were formed on BSA with DACone 10 but not with (S)-9 (Figure 2D). Moreover, the DACone 10 also reacted with several other model proteins, including the bovine beta-lactoglobuline (BLG) (Supplementary Figure 6A). Using BSA and BLG, we established that DACone adducts are produced only when using the clickable DACones 10 or 11 
169 (Figure 2E), suggesting that the terminal triple bond of the DACone pharmacophore is modified or masked after reaction. Finally, we could recapitulate the activation of $(S)-9$, but not of $(R)-9$, into protein-reactive species by immunopurified WT HSD17B11, but not by the S172L mutant (Figure 2F). This further supports an enantio-selective bioactivation of (S)-9 into the DACone 10 by HSD17B11.

Reaction of DACones with proteins. To further decipher the reaction of DACones with proteins, we used direct-infusion mass spectrometry to analyze BLG modified with the clickable DACone 10. Purified BLG contains two isoforms ( $A$ and $B$, differing by $86.0 \mathrm{Da}$ ) and, when incubated in a 1:3 molar ratio with DACone, both BLG isoforms were completely modified with the formation of one or two adducts of $\sim+242$ Da (Figure $\mathbf{2 G}$ ), which corresponds to the mass of the clickable DACone 10. Monitoring the absorbance spectra of modified BLG revealed that BLG gains an absorption band at $\sim 323 \mathrm{~nm}$ upon modification by DACone (Supplementary Figure 6B). Using this, we confirmed that both BLG and BSA are modified by the DACones $\mathbf{7}$ and $\mathbf{8}$ or their clickable analogues 10 and 11 (Supplementary Figure 6B,C). The shorter DACone 8 proved even more reactive, in line with its greater cytotoxicity (Figure 2C, Supplementary Figure 6B,C). Next, we assessed the selectivity of DACones towards amino acid residues in the whole proteome in an unbiased fashion. For this purpose, we incubated the DACones 10 and 11 with U2OS total cell extracts in PBS. We then used residue-specific chemoproteomics with isotopically labelled desthiobiotin azide (isoDTB) tags (27-29) coupled to a novel MSFragger-based FragPipe computational platform (30) to detect the modified amino acids on the enriched peptides. This revealed that both DACones reacted with cysteine and lysine side chains, with the expected modification being detected (Figure 2H, Supplementary Figure 6D,E,F, Supplementary File 1).

192 also modified by the probe but that their modification is lost during the workflow. We next confirmed 193 the reactivity of DACones with cysteine and lysine side chains by monitoring the appearance of 
the $\sim 323 \mathrm{~nm}$ absorbance band after reaction of the DACone 8 with isolated amino acids, using $N$ acetylated versions to prevent reactions with the $\mathrm{N}$-terminal amino group. At neutral $\mathrm{pH}$, DACones only reacted with $\mathrm{N}$-acetyl-L-cysteine (NAC) but not with $N_{\alpha}$-acetyl-L-lysine (NAK) (Supplementary Figure 6G, left spectrum), whereas at higher $\mathrm{pH}$ they reacted with both NAC and NAK (Supplementary Figure 6G, right spectrum), in agreement with the nucleophilic reactivity of the non-protonated $\varepsilon-\mathrm{NH}_{2}$ group of the lysine chain. No reaction was observed with $\mathrm{N}$-acetyl glycine (NAG), supporting that the reaction involves the side chain. The reaction with lysine side chains is compatible with the $p K_{a}$ value for the lysine $\varepsilon$-amino group that can be as low as $\sim 5$ in hydrophobic domains in proteins (31). In agreement, analysis of the sequence context of the amino acids identified as modified by the DACone 10 revealed an enrichment of hydrophobic amino acids around the modified lysines, which was not observed for the modified cysteines (Supplementary Figure 7A,B, Supplementary File 2). Using nuclear magnetic resonance (NMR), we characterized the products of the reaction of the short DACone 8 with NAC (Supplementary Figure $\mathbf{8 A}, \mathbf{B}$ ) or NAK (Supplementary Figure $\mathbf{8 C , D}$ ). This revealed that a covalent bond forms by addition of the thiol (NAC) or amino (NAK) group onto the terminal alkyne of the DACone head (Supplementary Figure 8E) and suggests a similar reaction with proteins (Figure 2I). The donor-acceptor extension of m-electron delocalization in the enone adducts (S$\mathrm{CH}=\mathrm{CH}-\mathrm{C}=\mathrm{O}$ for $\mathrm{NAC}, \mathrm{N}-\mathrm{CH}=\mathrm{CH}-\mathrm{C}=\mathrm{O}$ for $\mathrm{NAK}$ ) accounts for the additional absorption band observed for the DACone adducts with $\mathrm{N}$-acetyl amino acids. Altogether, our data show that DACones are highly reactive with proteins in vitro.

Bioactivated (S)-DACs lipoxidize multiple proteins in cells. Protein modification by lipidic DACs equates to their lipoxidation (a term used to designate the covalent modification of a protein by a reactive lipid (32)) by one or several $\mathrm{C} 17$ hydrophobic chain(s). Considering that protein palmitoylation (addition of a C16 lipidic chain) can trigger membrane tethering of proteins, we hypothesized that lipoxidation by DACs could affect protein localization and/or function and 
account for the cytotoxicity of bioactivated DACs in cells as described for other reactive lipids (32). To challenge this hypothesis in cells, we took advantage of the clickable DAC 9 (33) (Figure 2B). As observed for the DAC 3, the cytotoxicity of the clickable DAC 9 was enantiospecific, biased towards (S)-9, and dependent on bioactivation by HSD17B11 (Supplementary Figure 9A). Cells were treated with clickable (S)- or (R)-9 DACs, extracts prepared and click chemistry used to detect the covalent adducts of DACs onto proteins (26). Multiple modified proteins were detected in extracts from (S)-9-treated cells, while no adduct with (R)-9 was detected (Figure 3A).

To identify the proteins lipoxidized by DACs upon bioactivation, and inspired by previous studies $(34,35)$, we used streptavidin pull-down to isolate (S)-9-modified proteins after click chemistrymediated ligation of a biotin handle in extracts of treated cells and identified them using bottomup proteomics. 42 proteins were significantly enriched more than 2-fold in the (S)-9 condition as compared to (R)-9 (Figure 3B, Supplementary File 3), with three proteins being enriched more than 60-fold: BRAT1, PLIN3 and PSMD2. To validate the three main hits, we overexpressed BRAT1, PSMD2 and PLIN3 individually (in addition to TK1) as GFP fusions in U2OS cells (Supplementary Figure 9B), and used GFP pull-down to determine whether they were modified by clickable DAC 9 in cells. These proteins were found robustly modified by (S)-9 but not by $(R)-$ 9, especially BRAT1 and PSMD2, while GFP alone was not modified (Supplementary Figure 9C).

Among the three main hits, PSMD2 drew our attention as an essential protein in HAP-1 cells (36). PSMD2, also called Rpn1, is a critical non-catalytic subunit of the 19S regulatory particle of the $26 \mathrm{~S}$ proteasome, a large complex responsible for the ubiquitin-dependent degradation of cellular proteins. PSMD2 is essential for 19S assembly and for docking of ubiquitin, ubiquitin receptors and the deubiquitinase USP14 (37). Immunoprecipitation of endogenous PSMD2 from U2OS cells treated with clickable DAC confirmed that PSMD2 is covalently modified after treatment with the DAC (S)-9 but not with (R)-9 (Figure 3C). Moreover, the clickable DACone 10 efficiently modified 
PSMD2 in vitro (Supplementary Figure 9D). Using the (S)-DAC-resistant HAP-1 clones A1 and A4 (expressing V16D and S172L HSD17B11 mutants, respectively), we also confirmed that the modification of cellular proteins by (S)-9, including PSMD2, was dependent on HSD17B11 (Figure 3D and Supplementary Figure 9E). Our proteomics approach also revealed that, in addition to PSMD2, a cluster of proteins involved in protein quality control (PQC) was also modified by the DAC (S)-9 (Figure 3B), including several protein disulfide isomerases (PDIA1/P4HB, PDIA6 and TMX1), thioredoxin reductases (TXNDC5 and TXNRD1) and protein chaperones (the ER-resident HSP70, HSPA5/GRP78/BiP; and HSP90AB1), the alteration of which likely also contributes to the DAC cytotoxic effect. Altogether, these data show that (S)-DACs are bioactivated by HSD7B11 into highly reactive DACones that covalently lipoxidize nearby proteins, including essential proteins involved in PQC such as PSMD2, a critical subunit of the ubiquitin-proteasome system (UPS).

We then used click-based imaging to monitor the localization of DAC-modified proteins. (S)-9 gave a strong nuclear and cytoplasmic staining, the latter being evocative of ER and mitochondrial membranes (Figure 3E). In agreement, we observed a co-occurrence of (S)-9-click staining with markers of ER (Supplementary Figure 10A) and mitochondria (Supplementary Figure 10B,C). The lack of staining in cells treated with the inactive $(R)-9$ (Figure 3E) supported that the staining corresponds to DAC-modified proteins. No staining was observed with (S)-3, supporting that the $\mathrm{C} \equiv \mathrm{CH}$ group of the dialkynylcarbinol head is modified after bioactivation and subsequent reaction with proteins (as shown in Figure 2I). Since GFP-BRAT1 is the protein that was the most robustly modified by DACs in cells (Supplementary Figure 9C), we pre-extracted soluble proteins with mild nonionic detergent to assess GFP-BRAT1 association to subcellular compartments. Under these conditions, most GFP-BRAT1 was removed by the pre-extraction in untreated cells, as expected for a soluble protein, while it was retained to subcellular compartments evocative of ER and nucleus after treatment with (S)-3 (Figure 3F). These data suggest that protein lipoxidation 
by bioactivated DACs results, at least for some of them, into their relocalization to cellular membranes.

(S)-DACs trigger ER-stress, inhibition of ubiquitin-proteasome system (UPS) and apoptosis. In agreement with (S)-DAC impairing PQC, we observed that treatment of cells by (S)3 triggers ER swelling as shown by the appearance of a large cytoplasmic vacuole between 4 and $8 \mathrm{~h}$ of treatment that preceded cell death (Figure 4A). The use of a GFP variant targeted and retained into the ER confirmed that these vacuoles derived from this compartment (Figure 4B), while a mCherry protein addressed to mitochondria in the same cells showed that (S)-DAC treatment concomitantly triggered mitochondrial fission, a hallmark of cell stress (Supplementary Figure 11, see also Supplementary movie 1). ER swelling is a feature of ER-stress, which can result from the accumulation of unfolded proteins within the ER and can be triggered by various defects of PQC such as inhibition of the UPS, as seen with the UPS inhibitor MG132 (Supplementary Figure 12A). In agreement with (S)-3 cytotoxicity being mediated by the accumulation of unfolded proteins, vacuolization and cell death induced by (S)-3 could be blocked by inhibition of protein synthesis by cycloheximide (CHX, Supplementary Figure 12B). (S)-3 also triggered a strong accumulation of the chaperone HSP70 and of the cell stress response protein p21, similarly to MG132 (Figure 4C) or PSMD2 depletion using siRNA (Supplementary Figure 12C). It is noteworthy that ER-stress itself can trigger UPS inhibition, likely through consuming free ubiquitin (38). In agreement with this hypothesis, we observed that (S)-3 induces the accumulation of poly-ubiquitinated proteins (Figure 4D), a hallmark of UPS inhibition, and blocked the degradation of an artificial substrate of the UPS system in a manner similar to MG132 (Figure 4E,F). Similarly to MG132, (S)-3 also blocked the assembly of the protein 53BP1 into foci at sites of DNA double-strand breaks (Supplementary Figure 12D), a process that depends on the local de novo DNA damage-induced ubiquitination of histones (39), thereby confirming depletion of free ubiquitin by treatment with (S)-3. It is noteworthy that (S)-3 treatment itself did not induce DNA 
damage nor blocked ATM activation, an important component of the DNA damage response (Supplementary Figure 12D). Accumulation of unfolded proteins in the ER activates the Unfolded Protein Response (UPR) which helps maintain ER protein homeostasis by reducing the influx of proteins into the ER and by increasing the activity of ER protein quality control mechanisms. The UPR is initiated by the activation of three signal transducers: IRE1 $\alpha$, PERK and ATF6, each controlling a specific aspect of the UPR (40). IRE1 $\alpha$ is a ER-resident transmembrane protein, the activation of which results from its homodimerization mediated by its luminal domain, which is controlled by ER-resident chaperones including HSPA5/GRP78/BiP. IRE1 $\alpha$ activation triggers its autophosphorylation, which is used as a marker of UPR activation. In agreement with (S)-3 triggering unfolded proteins accumulation and UPR activation, we observed that treatment with (S)-3 induced the rapid autophosphorylation of IRE1 $\alpha$, preceding the accumulation of cytoplasmic HSP70 (Figure 4G). Ultimately, (S)-3 treatment resulted in apoptosis, as marked by PARP-1 cleavage (Figure 4G), in a caspase inhibitor (z-VAD-fmk)-sensitive manner (Figure 4H). Caspase inhibition blocked cell death but not the vacuolization process (Supplementary Figure 12E). Altogether, these results show that (S)-3, once bioactivated by HSD17B11, covalently modifies multiple proteins including critical components of the PQC, resulting in ER-stress, inhibition of the UPS and activation of the UPR, ultimately resulting in apoptotic cell death.

Identification of new SDR-specific prodrugs. Our discovery that an SDR, HSD17B11, bioactivates a secondary alcohol prodrug by oxidation into the corresponding ketone is particularly interesting given that the SDR superfamily is one of the largest protein superfamilies, with over 500,000 members found in most forms of life. This means that this mechanism of prodrug activation could be exploited to develop an extensive range of new drugs and compounds to kill cells or organisms expressing specific SDRs with high selectivity. SDRs use NAD(H) or NADP(H) cofactors to perform oxidoreductase, lyase or isomerase activities on a large variety of substrates including steroids, retinoic acids, lipids, polyols, sugars, nucleotides and xenobiotics (41). In vitro, 
SDR enzymes can frequently catalyze both oxidation and reduction, depending on the supplied co-factor. In cells, however, they show directionality, which depends on their sub-cellular localization and cofactor availability. We first determined whether other SDRs with the proper in cellulo directional polarity could activate other secondary alkynylcarbinol-containing compounds into cytotoxic species. We found that the $A A C(S)-4$ (with a terminal $C=\mathrm{CH}_{2}$ group, Figure $5 \mathrm{~A}$ ), despite its activity being strongly reduced in DAC-resistant clone A4 ( 17 fold, Supplementary Figure 3B), still retained some cytotoxicity $\left(\mathrm{IC}_{50} \sim 2.6 \mu \mathrm{M}\right)$ on these cells, possibly through bioactivation by a second dehydrogenase. To identify such a dehydrogenase, EMS was used to mutagenize the DACR clone \#A4 once again. This mutagenized population was selected with a lethal concentration of $10 \mu \mathrm{M}(S)-4$ and over twenty resistant clones (AACR clones) were isolated. Among those, we selected seven, which all showed similar increased resistance to (S)-4 (Figure 5A), and submitted them to RNA-seq analysis. This allowed the identification of an average of six coding mutations in each clone (Supplementary Figure 13A), and analysis revealed that the RDH11 gene carried point mutations in five of these seven clones (Supplementary Figure $13 \mathrm{~A}, \mathrm{~B})$. Further analysis revealed that the clone $\mathrm{A} 6$ contained two alleles of $R D H 11$, each with a different point mutation (Figure 5B), and RDH11 expression was severely downregulated in the clone B4 (Supplementary Figure 13C). In conclusion, the RDH11 gene was mutated (Figure 5C) or downregulated in all the AACR clones, implicating it as an SDR, with similar prodrug bioactivation capacity as HSD17B11, that mediates AAC (S)-4 toxicity.

The human RDH11 gene codes for retinol dehydrogenase 11 (also called PSDR1 or SDR7C1), a member of the SDR superfamily which also localizes to the ER (42) where it uses NADP+ to catalyze the conversion of retinol (Figure 5D, preferentially the 11-cis, all-trans and 9-cis isomers) into retinal through oxidation of the $C-15$ carbinol center, with a pro- $R$ hydrogen specificity(43). Full-length $\mathrm{RDH} 11$ protein was not detectable in any of the AACR clones, suggesting that all the identified mis-sense mutations decrease RDH11 stability (Figure 5E). To validate the ability of 
$\mathrm{RDH} 11$ to mediate some of the (S)-4 cytotoxic effects, we compared its activity on U2OS, U2OS KO HSD17B11 and U2OS KO HSD17B11 cells in which RDH11 was inactivated using CRISPR/Cas9 (Supplementary Figure 14A). In this panel, we confirmed that, while HSD17B11 was responsible for the $\mathrm{nM}$ activity of the AAC (S)-4 (48-fold IC 50 increase as a result of HSD17B11 inactivation), the remaining toxicity of (S)-4 in HSD17B11 KO cells was further decreased by inactivating $\mathrm{RDH} 11$ (6-fold $\mathrm{IC}_{50}$ increase by $\mathrm{RDH} 11$ inactivation, Supplementary Figure 14B). Comparison of the activity of (S)-3 and (S)-4 on U2OS KO [HSD17B11+RDH11] complemented either by HSD17B11-GFP or RDH11 (Supplementary Figure 14C) revealed that RDH11 bioactivates preferentially $(\mathrm{S})-\mathbf{4}\left(\mathrm{IC}_{50} \sim 0.28 \mu \mathrm{M}\right.$, with a terminal $\mathrm{C}=\mathrm{CH}_{2}$ group) over $(\mathrm{S})-3\left(\mathrm{IC}_{50} \sim 1.92\right.$ $\mu \mathrm{M}$, with a terminal $\mathrm{C} \equiv \mathrm{CH}$ group, Supplementary Figure 14D), but also established that HSD17B11 was much more efficient than RDH11 for the bioactivation of either molecule $\left(\mathrm{IC}_{50}<\right.$ $40 \mathrm{nM})$.

As a proof-of-principle of the potential value of these discoveries for designing novel prodrugs with controlled cytotoxic activity, we attempted to design a new prodrug whose cytotoxic effects would depend more on the RDH11 SDR. We used WT U2OS or U2OS inactivated for HSD17B11, $\mathrm{RDH} 11$ or both (Figure $\mathbf{5 F}$ ) to test several AAC analogues. Introduction of a second secondary carbinol function in the AAC structure, generating the AlkenylAlkynylDiCarbinol 12 (AADC), reduced its bioactivation by HSD17B11, while leaving intact its RDH11-dependent activation and thereby generating a new prodrug equally bioactivated by HSD17B11 and RDH11 (Figure 5G). As mixtures of diastereoisomers were used for this experiment, lower $\mathrm{IC}_{50}$ can be expected with selected AADC enantiomers, especially with the external carbinol center in the RDH11-preferred (S) configuration.

Another SDR, HPGD, also called 15-PGDH, PGDH1 or SDR36C1, is responsible for the inactivation of prostaglandins through oxidation of the (S)-C-15 carbinol center in a NAD+dependent manner (Figure 5H) (44). HPGD expression is tissue-restricted (prostate and bladder) 
and null in U2OS cells (Broad Institute Cancer Cell Line Encyclopedia RNA-seq dataset). To determine whether this SDR could also bioactivate potential prodrugs, we used U2OS inactivated for HSD17B11 and overexpressing GFP alone or HPGD-GFP (Figure 5I), and screened a small collection of lipidic alkynylcarbinols. We found that the AllAC $\left(S, S_{a}\right)-5$ was selectively bioactivated by HPGD, resulting in an $\mathrm{IC}_{50}$ of $\sim 147 \mathrm{nM}$ in HPGD-overexpressing cells vs normal U2OS (Figure 5J). Thus, this mechanism of action is likely a general property of SDRs that could be exploited to develop a wide range of tailored prodrugs to cause selective cytotoxicity.

\section{Discussion}

Through a powerful framework (13) (see Supplementary Note 1), our study reveals the original mode of action of a large family of natural and synthetic cytotoxic lipids characterized by a chiral terminal functional alkynylcarbinol pharmacophore. We show that these molecules are oxidized in an enantiospecific manner by a specific SDR, HSD17B11, converting them into an alkynylketone species (ynones). Oxidation of DACs produces dialkynylketones (DACones) that proved to be highly protein-reactive electrophiles, forming Michael adducts with cysteines and lysines. Consequently, bioactivated DACs modify several proteins in cells, resulting in their lipoxidation by a C17 lipidic chain. Lipoxidation of a protein can modify its solubility, folding, interactions, activity and/or localization (32). In agreement, DAC treatment triggers the association of BRAT1, one of the most DAC-modified proteins, to ER and nuclear membranes (Figure 3F). Covalent modification of BRAT1 by the natural diterpene curcusone D was recently reported and resulted in BRAT1 degradation and reduced DNA damage response (45). Regarding (S)-DAC, in addition to BRAT1, multiple proteins involved in mechanisms of PQC are also lipoxidized. Considering that lipoxidation of a single protein can inhibit the UPS (46), the simultaneous modification of several critical actors of $P Q C$ is likely to result in an acute proteotoxic stress. In agreement with the general effects of protein lipoxidation, DAC treatment triggers ER-stress and inhibition of the UPS (each 
one fueling the other) (38). This leads to the early activation of the UPR marked by IRE1 $\alpha$ autophosphorylation. In addition to unfolded proteins accumulation, UPR activation could also be the result of HSPA5/GRP78/BiP lipoxidation and/or tethering of multiple proteins to ER membranes. Finally, (S)-DACs also quickly induce mitochondrial fission and caspase-dependent apoptosis (Figure 6). Of note, hundreds of known cytotoxic natural compounds have one or several alkynylcarbinol motifs. The mechanism of action identified here could thus be shared in its principles (enantiospecific bioactivation into protein-reactive lipids) by these cytotoxic molecules (see Supplementary Note 2).

Our work also provides a proof-of-concept that new pro-cytotoxic agents can be designed to be bioactivated through an enantiospecific oxidation catalyzed by selected SDRs. We exemplified this with three different human dehydrogenases, HSD17B11, RDH11 and HPGD (Figure 6). We also show here that multiple human cell lines derived from osteosarcoma, a rare pediatric cancer, were particularly sensitive to (S)-DACs (Supplementary Figure 4C), suggesting that HSD17B11and more generally SDR-bioactivated prodrugs could find anticancer applications, especially considering that 71 different SDRs are found in humans (47). For example, HSD3B1-specific prodrugs could prove useful to treat castration-resistant prostate cancers, since the stabilized N367T

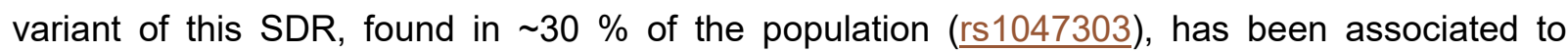
resistance to androgen deprivation therapies by allowing self-sufficient production of proproliferative androgens by prostate cancer cells (48-50).

Of note, another family of diyne molecules, the enediynes, are already used in anticancer treatments (see Supplementary Note 3). Beyond that, the SDR superfamily is one of the largest, with representatives in all known life forms, except viruses: 507673 SDRs are currently identified in the Uniprot database (in 7546 species, Pfam ID: PF00106). A bioinformatic classification of SDRs has revealed that among the 314 SDR subfamilies identified (51), half are specific to bacteria. This offers the prospect of designing antibiotics with novel mechanisms of action. 
419 Finally, our findings extend the toolbox of protein-reactive warheads with the identification of the 420 DACone motif as a potent reactive group toward the thiol and amino groups of the side chains of 421 cysteine and lysine, respectively. This reaction is quantitative, without co-product and operating 422 in aqueous buffer at room temperature, making it well suited for many applications. In our study, 423 multiple proteins could be functionalized by a terminal alkyne motif using clickable DACone 10 or 42411 and the resulting linkage was found to be highly stable. The reactive species could also be 425 readily produced in situ by using the appropriate SDR with its co-factor (see Figure 2F). Our 426 unbiased study of the DACones reactivity using the isoDTB-ABPP approach (30) provides the first 427 insights into the proteome-wide reactivity of these novel electrophiles. Reactive lysines have been 428 mapped on functional domains of human proteins $(52,53)$ and could be targeted through exploiting 429 this new reactive entities supplied exogenously or generated in situ, thereby offering new avenues 430 for protein functionalization or covalent inhibitors design. 


\section{Methods}

432 Plasmids. Detailed information regarding the plasmids used and generated in this study are 433 provided in the table below. Plasmids generated in this study have been produced i) by ligating 434 annealed primers into Bbsl digested plasmids (for cloning of sgRNAs) or ii) by ligating digested 435 PCR-amplified cDNAs into dephosphorylated plasmids. Phusion DNA polymerase, FastDigest 436 restrictions enzymes and FastAP phosphatase were used (Thermo Fisher Scientific). For all 437 plasmids, DNA sequencing (Mix2Seq, Eurofins Genomics) was used with the specified primers, 438 to confirm that the desired sequence was inserted. All new plasmids have been deposited on 439 Addgene

\begin{tabular}{|c|c|c|c|c|c|c|c|}
\hline Plasmid name & $\begin{array}{l}\text { Template } \\
\text { for PCR- } \\
\text { based } \\
\text { cloning }\end{array}$ & $\begin{array}{l}\text { Primers for PCR- } \\
\text { based cloning, } \\
\text { sequencing or } \\
\text { oligonucleotides } \\
\text { for annealing- } \\
\text { based cloning }\end{array}$ & Cloned in & $\begin{array}{l}\text { Cloning } \\
\text { sites }\end{array}$ & $\begin{array}{l}\text { Polymor } \\
\text { phism }\end{array}$ & $\begin{array}{l}\text { Addgene } \\
\text { ID }\end{array}$ & Reference \\
\hline ERmoxGFP & & & & & & 68072 & (54) \\
\hline Ub-G76V-YFP & & & & & & 11949 & (38) \\
\hline mCherry-Mito-7 & & & & & & 55102 & (55) \\
\hline $\begin{array}{l}\text { pEGFP-N1-ATG- } \\
\text { FLAGC }\end{array}$ & & & & & & 60360 & $(56)$ \\
\hline $\begin{array}{l}\text { pEGFP-N1- } \\
\text { HSD17B11-WT- } \\
\text { FLAGC }\end{array}$ & $\begin{array}{l}\text { RT-PCR } \\
\text { from wild- } \\
\text { type HAP- } \\
1\end{array}$ & $\begin{array}{l}\text { RT: } \\
\text { HSD17B11-RNA-Rv } \\
\text { HSD17B11-RNA-Fw } \\
\text { Cloning: HSD17B11- } \\
\text { F-Xhol } \\
\text { HSD17B11-R-Mlul } \\
\text { Sequencing: } \\
\text { SEQ-HSD17B11-F1 } \\
\text { SEQ-HSD17B11-R1 }\end{array}$ & $\begin{array}{l}\text { pEGFP-N1- } \\
\text { FLAGC, } \\
\text { Addgene } \\
\# 60360(56)\end{array}$ & Xhol+Mlul & $\begin{array}{l}\text { rs65319 } \\
85\end{array}$ & 161903 & This work \\
\hline $\begin{array}{l}\text { pEGFP-N1- } \\
\text { HSD17B11- } \\
\text { S172L-FLAGC }\end{array}$ & $\begin{array}{l}\text { RT-PCR } \\
\text { from } \\
\text { DACR\#A4 } \\
\text { HAP-1 } \\
\end{array}$ & $\begin{array}{l}\text { HSD17B11-RNA-Rv } \\
\text { for RT } \\
\text { HSD17B11-F-Xhol } \\
\text { HSD17B11-R-Mlul }\end{array}$ & $\begin{array}{l}\text { pEGFP-N1- } \\
\text { FLAGC, } \\
\text { Addgene } \\
\# 60360(56)\end{array}$ & Xhol+Mlul & $\begin{array}{l}\text { rs65319 } \\
85\end{array}$ & 161904 & This work \\
\hline $\begin{array}{l}\text { pICE-EGFP- } \\
\text { FLAG-PLIN3 }\end{array}$ & $\begin{array}{l}\text { IMAGE } \\
\text { clone } \\
\# 3833411 \\
\text { (Source } \\
\text { Bioscienc } \\
\text { e) }\end{array}$ & $\begin{array}{l}\text { Cloning: } \\
\text { PLIN3-F-Xhol } \\
\text { PLIN3-R-Notl } \\
\text { Sequencing: } \\
\text { SEQ-GFPC-F } \\
\text { SEQ-PLIN3-F } \\
\text { SEQ-BGH-R } \\
\end{array}$ & $\begin{array}{l}\text { plCE-EGFP- } \\
\text { FLAG- } \\
\text { Ku70siR- } \\
\text { WT; } \\
\text { Addgene } \\
\text { \#46961 (57) }\end{array}$ & Xhol+Notl & & 161918 & This work \\
\hline $\begin{array}{l}\text { pEGFP-C1-FLAG- } \\
\text { BRAT1 }\end{array}$ & $\begin{array}{l}\text { IMAGE } \\
\text { clone } \\
\text { \#3839985 } \\
\text { (Source } \\
\text { Bioscienc } \\
\text { e) }\end{array}$ & $\begin{array}{l}\text { Cloning: } \\
\text { BRAT1-F-Notl } \\
\text { BRAT1-R-EcoRI } \\
\text { Sequencing: } \\
\text { SEQ-GFPC-F } \\
\text { SEQ-BRAT1-F1 } \\
\text { SEQ-BRAT1-F2 } \\
\text { SEQ-SV40PA-R }\end{array}$ & $\begin{array}{l}\text { pEGFP-C1- } \\
\text { FLAGN; } \\
\text { Addgene } \\
\# 46956 \text { (57) }\end{array}$ & $\begin{array}{l}\text { Notl+Eco } \\
\text { RI }\end{array}$ & & 161920 & This work \\
\hline $\begin{array}{l}\text { plCE-EGFP- } \\
\text { FLAG-PSMD2 }\end{array}$ & $\begin{array}{l}\text { IMAGE } \\
\text { clone } \\
\text { \#2822191 } \\
\text { (Source }\end{array}$ & $\begin{array}{l}\text { Cloning: } \\
\text { PSMD2-F-Xhol } \\
\text { PSMD2-R-Notl } \\
\text { Sequencing: }\end{array}$ & $\begin{array}{l}\text { pICE-EGFP- } \\
\text { FLAG- } \\
\text { Ku70siR- } \\
\text { WT; }\end{array}$ & Xhol+Notl & & 161917 & This work \\
\hline
\end{tabular}




\begin{tabular}{|c|c|c|c|c|c|c|c|}
\hline & $\begin{array}{l}\text { Bioscienc } \\
\text { e) }\end{array}$ & $\begin{array}{l}\text { SEQ-GFPC-F } \\
\text { SEQ-PSMD2-F1 } \\
\text { SEQ-PSMD2-F3 } \\
\text { SEQ-PSMD2-R1 } \\
\text { SEQ-PSMD2-R2 } \\
\text { SEQ-BGH-R } \\
\end{array}$ & $\begin{array}{l}\text { Addgene } \\
\# 46961 \text { (57) }\end{array}$ & & & & \\
\hline $\begin{array}{l}\text { pICE-EGFP- } \\
\text { FLAG-TK1 }\end{array}$ & $\begin{array}{l}\text { IMAGE } \\
\text { clone } \\
\# 2966331 \\
\text { (Source } \\
\text { Bioscienc } \\
\text { e) }\end{array}$ & $\begin{array}{l}\text { Cloning: } \\
\text { TK1-F-Xhol } \\
\text { TK1-R-Notl } \\
\text { Sequencing: } \\
\text { SEQ-GFPC-F } \\
\text { SEQ-BGH-R }\end{array}$ & $\begin{array}{l}\text { pICE-EGFP- } \\
\text { FLAG- } \\
\text { Ku70siR- } \\
\text { WT; } \\
\text { Addgene } \\
\text { \#46961 (57) }\end{array}$ & Xhol+Notl & & 161919 & This work \\
\hline $\begin{array}{l}\text { pEGFP-N1-HPGD- } \\
\text { FLAGC }\end{array}$ & $\begin{array}{l}\text { IMAGE } \\
\text { clone } \\
\# 3638799 \\
\text { (Source } \\
\text { Bioscienc } \\
\text { e) }\end{array}$ & $\begin{array}{l}\text { Cloning: } \\
\text { HPGD-F-Xhol } \\
\text { HPGD-R-Mlul } \\
\text { Sequencing: } \\
\text { SEQ-CMV-F } \\
\text { SEQ-GFPN-R }\end{array}$ & $\begin{array}{l}\text { pEGFP-N1- } \\
\text { FLAGC, } \\
\text { Addgene } \\
\# 60360 \text { (56) }\end{array}$ & Xhol+Mlul & & 161915 & This work \\
\hline pE-N1-RDH11 & $\begin{array}{l}\text { RT PCR } \\
\text { from wild- } \\
\text { type HAP- } \\
1\end{array}$ & $\begin{array}{l}\text { RT: } \\
\text { RDH11-RNA-Rv } \\
\text { RDH11-RNA-Fw } \\
\text { Cloning: } \\
\text { RDH11-F-HindlII } \\
\text { RDH11-R-Notl } \\
\text { Sequencing: } \\
\text { SEQ-CMV-F } \\
\text { SEQ-SV4OPA-R } \\
\end{array}$ & $\begin{array}{l}\text { pEGFP-N1- } \\
\text { FLAGC, } \\
\text { Addgene } \\
\# 60360 \text { (56) }\end{array}$ & $\begin{array}{l}\text { HindlII+No } \\
\mathrm{tl}\end{array}$ & $\begin{array}{l}\text { rs17854 } \\
678\end{array}$ & 161916 & This work \\
\hline $\begin{array}{l}\text { pCAG-eSpCas9- } \\
\text { 2A-GFP-sgRNA- } \\
\text { HSD17B11 }\end{array}$ & & $\begin{array}{l}\text { Annealed primers: } \\
\text { HSD17B11-sgRNA- } \\
\text { S } \\
\text { HSD17B11-sgRNA- } \\
\text { AS } \\
\text { Designed with } \\
\text { Benchling } \\
\text { Sequencing : } \\
\text { SEQ-U6-F }\end{array}$ & $\begin{array}{l}\text { pCAG- } \\
\text { eSpCas9- } \\
\text { 2A-GFP, } \\
\text { Addgene } \\
\# 79145\end{array}$ & Bbsl & & 161923 & This work \\
\hline $\begin{array}{l}\text { pCAG-eSpCas9- } \\
\text { 2A-GFP-sgRNA- } \\
\text { RDH11 }\end{array}$ & & $\begin{array}{l}\text { Annealed primers : } \\
\text { RDH11-sgRNA-S } \\
\text { RDH11-sgRNA-AS } \\
\text { Designed with } \\
\text { Benchling : } \\
\text { Sequencing : } \\
\text { SEQ-U6-F }\end{array}$ & $\begin{array}{l}\text { pCAG- } \\
\text { eSpCas9- } \\
\text { 2A-GFP, } \\
\text { Addgene } \\
\# 79145\end{array}$ & Bbsl & & 161924 & This work \\
\hline
\end{tabular}
were ordered from Eurofins Genomics.

\begin{tabular}{|l|l|l|}
\hline ID & Sequence 5' to 3' & $\begin{array}{l}\text { Embedded } \\
\text { restriction } \\
\text { site }\end{array}$ \\
\hline Plasmid sequencing & & \\
\hline SEQ-CMV-F & GTAGGCGTGTACGGTGGGAGG & \\
\hline SEQ-BGH-R & TAGAAGGCACAGTCGAGG & \\
\hline SEQ-GFPC-F & CATGGTCCTGCTGGAGTTCGTG & \\
\hline SEQ-GFPN-R & CTCCTCGCCCTTGCTCACC & \\
\hline SEQ-SV40PA-R & GCAAGTAAAACCTCTACAAATGTGGTATGG & \\
\hline SEQ-U6-F & TGGACTATCATATGCTTACCG & \\
\hline BRAT1 & & NotI \\
\hline BRAT1-F-NotI & CGCGCGGCCGCATGGACCCAGAATGCGCCC & EcoRI \\
\hline BRAT1-R-EcoRI & CGCGAATTCTCAGTAGCAGTCGGCCTCGTCC & \\
\hline
\end{tabular}


444

445

446

\begin{tabular}{|c|c|c|}
\hline SEQ-BRAT1-F1 & AGAGTCCTTGTGCTCCGCGG & \\
\hline SEQ-BRAT1-F2 & GCCCCTGCCTCCAGTGTGG & \\
\hline \multicolumn{3}{|l|}{ HPGD } \\
\hline HPGD-F-Xhol & GGCCTCGAGCCACCATGCACGTGAACGGCAAAGTGG & Xhol \\
\hline HPGD-R-Mlul & GGCACGCGTTTGGGTTTTTGCTTGAAATGG & Mlul \\
\hline \multicolumn{3}{|l|}{ HSD17B11 } \\
\hline HSD17B11-RNA-Fw & ACACCAAACGCTCGCAGCC & \\
\hline HSD17B11-RNA-Rv & CACTATTAGATGACATCAACCTAAACCTG & \\
\hline SEQ-HSD17B11-F1 & GAAGGTGAAGGCAGAAATTGGAG & \\
\hline SEQ-HSD17B11-R1 & ACATGTCCAGCTGCCGAAGC & \\
\hline HSD17B11-F-Xhol & CCGCTCGAGCCACCATGAAATTTCTTCTGGACATCCTCC & Xhol \\
\hline HSD17B11-R-Mlul & CCGACGCGTTTGCGCTTTCATTTTATATCCAATAACTGC & Mlul \\
\hline HSD17B11-sgRNA-S & CACCGTGTAATCAGCACGATTTCGC & \\
\hline HSD17B11-sgRNA-AS & AAACGCGAAATCGTGCTGATTACAC & \\
\hline \multicolumn{3}{|l|}{ PLIN3 } \\
\hline PLIN3-F-Xhol & GCGCTCGAGTCTGCCGACGGGGCAGAG & Xhol \\
\hline PLIN3-R-Notl & CGCGCGGCCGCCTACTTCTTCTCCTCCGGGGC & Notl \\
\hline SEQ-PLIN3-F & CTGTGCAGAGCGGCGTGG & \\
\hline \multicolumn{3}{|l|}{ PSDM2 } \\
\hline PSMD2-F-Xhol & GCGCTCGAGATGGAGGAGGGAGGCCGG & Xhol \\
\hline PSMD2-R-Notl & CGCGCGGCCGCTTAGAGATCATAATTGGGGTTCTTCC & Notl \\
\hline SEQ-PSMD2-F1 & TGCAGAGCATGAGGCTTGCG & \\
\hline SEQ-PSMD2-F3 & CAGGGAGTGGCTGTTCTGGG & \\
\hline SEQ-PSMD2-R1 & TGTGCTCCCATGTCAGCAGG & \\
\hline SEQ-PSMD2-R2 & CAGCCCTCCGGAGTGTAGGC & \\
\hline \multicolumn{3}{|l|}{$\mathrm{RDH} 11$} \\
\hline RDH11-RNA-Fw & GCTCTGGTGCCGCTGCAGCC & \\
\hline RDH11-RNA-Rv & AGTCTTCTCTTGGGTCCAACTGG & \\
\hline RDH11-F-HindIII & GCCAAGCTTGCCACCATGGTTGAGCTCATGTTCCCGC & HindlII \\
\hline RDH11-R-Notl & CGCGCGGCCGCTTTAGTCTATTGGGAGGCCCAGCAGG & Notl \\
\hline RDH11-sgRNA-S & CACCGAGTTGATGTACACACCCCAC & \\
\hline RDH11-sgRNA-AS & AAACGTGGGGTGTGTACATCAACTC & \\
\hline \multicolumn{3}{|l|}{ TK1 } \\
\hline TK1-F-Xhol & CGCCTCGAGAGCTGCATTAACCTGCCCACTGTGC & Xhol \\
\hline TK1-R-Notl & CGCGCGGCCGCTCAGTTGGCAGGGCTGCATTGC & Notl \\
\hline
\end{tabular}

Cell lines and treatments. U2OS (ATCC), SAOS-2 (ATCC), 143B (Sigma-Aldrich), HOS (ECACC/Sigma-Aldrich), HS5 (ATCC), G292 clone 141B1 (ECACC/Sigma-Aldrich), HCT-116 (Horizon Discovery), A549 (ATCC), HT-1080 (ATCC), MDA-MB-436 (ATCC), SK-MEL-28 (ATCC), DLD-1 (ATCC), HEK293T (ATCC), MRC5-SV (ECACC/Sigma-Aldrich), HeLa (ATCC) and PC3 (ATCC) cells were grown in DMEM 10\% FBS; CAPAN1 (ATCC) in IMDM 20\% FBS; T47D (ATCC) and CAPAN2 (ATCC) cells in RPMI1640 10\% FBS with Glutamax-I; HAP-1 (58) (Horizon Discovery) in IMDM 10\% FBS and BJ-hTERT (gift from R. Weinberg, Whitehead Institute, Cambridge, USA) in DMEM 15\% FBS 16\% M199; human adult primary osteoblast (Cell Applications Inc., Sigma-Aldrich) in human osteoblast growth medium (Cell Applications Inc., 
Sigma-Aldrich). All cells media, except human osteoblast growth medium, contained penicillin and streptomycin (pen./strep.; Thermo Fisher Scientific) and cells were grown at $37^{\circ} \mathrm{C}$ in $5 \% \mathrm{CO}_{2}$ humidified incubator. Cells were used at low passage and routinely confirmed free of Mycoplasma. Cells were treated in complete growth medium except when stated otherwise.

Plasmid transfection and stable cell generation. Cells were transfected at $90 \%$ confluency in $60 \mathrm{~mm}$ dishes and using $5 \mu \mathrm{g}$ DNA and lipofectamine 2000 (Thermo Fisher Scientific) following manufacturer's instructions. The day after transfection, cells were seeded at limiting dilution in 140 $\mathrm{mm}$ dishes. Selection of stable transfectants was performed either with $0.4 \mathrm{mg} / \mathrm{mL} \mathrm{G} 418$ or 0.2 $\mu \mathrm{g} / \mathrm{mL}$ puromycin. Individual clones were isolated. Homogeneous transgene expression was confirmed by monitoring cell fluorescence (for GFP tagged constructs) or by immunofluorescence.

CRISPR/Cas9-mediated gene inactivation. Cells were transfected with pCAG-eSpCas9-2AGFP plasmids coding for the S. pyogenes Cas9 K848A K1003A R1060A variant, which displays reduced off-target editing (59), and co-expressing a guide against HSD17B11 or RDH11. One week after transfection, cells could be plated at limiting dilution to perform selection of individual clones, which were analysed for proper target inactivation. Rescue experiments were performed (with HSD17B11 or RDH11) to rule out off-target-related effects.

Small-interfering RNA (siRNA)-mediated depletion. siRNA with a dTdT 3'extension were ordered from Eurofins Genomic against the following sequences: Control (Ctrl, target Firefly Luciferase) CGUACGCGGAAUACUUCGA, HSD17B11 \#3 (ORF) CACAAGATCCTCAGATTGAAA, HSD17B11 \#5 (3'-UTR) AACCGTTTATTTAACATATAT, $\begin{array}{lllll}\text { PSMD2 } & \text { \#5 (ORF) TGGGTGTGTTCCGAAAGTTA, } & \text { PSMD2 \#9 (3'-UTR) }\end{array}$ AAGGTTGTTCAATAAAGACTT. 250000 U2OS cells were seeded in 6-well plate the day before the first transfection. The day after, cells were transfected with $50 \mathrm{nM}$ of each siRNA (Control, PSMD2 or HSD17B11) for 4-5 h according to manufacturer's instruction before the medium being 
replaced by DMEM 10\% FBS without antibiotics. A second transfection was performed the day after. Cells were seeded in $60 \mathrm{~mm}$ dishes the day before being used for experiments.

Cell viability assays. Cell viability was analyzed using SulfoRhodamine B assays (SRB). Cells were seeded in 96-well plates $24 \mathrm{~h}$ before being treated continuously for $72 \mathrm{~h}$ with the indicated concentration of each molecule. For the experiments described in Figure $\mathbf{2 C}$, cells were gently washed twice with PBS $\mathrm{Ca}^{2+} / \mathrm{Mg}^{2+}$ just before treatment (to remove residual media), treated with drugs for $1 \mathrm{~h}$ in PBS containing $\mathrm{CaCl}_{2}$ and $\mathrm{MgCl}_{2}$ (to maintain cellular adhesion), then rinsed twice with complete medium (to remove residual drug), followed by a $72 \mathrm{~h}$ post-incubation in complete culture medium. For analysis, cells were fixed for $1 \mathrm{~h}$ at $4{ }^{\circ} \mathrm{C}$ by addition of cold trichloroacetic acid at a $3.33 \%$ final concentration. After being washed four times with water and dried, cells were stained by a 30 min incubation in a solution of $0.057 \%$ (wt:vol) SRB in $1 \%$ acetic acid. The wells were washed four times with $1 \%$ acetic acid, dried and the dye was resuspended by a $2 \mathrm{~h}$ incubation in a $10 \mathrm{mM}$ Tris-Base solution. Absorbance at $490 \mathrm{~nm}$ of each well was measured ( $\mu$ Quant plate reader, Bio-tek) and used as a readout of cell number. For calculation, background absorbance was subtracted to each value and the data were normalized to the value measured in untreated wells. Each point was measured in duplicate and the graphs correspond to at least three independent experiments. $I_{50}$ were computed with the GraphPad Prism software using a non-linear regression to a four-parameter logistic curve (log[inhibitor] vs response; variable slope).

Analysis of RNA expression levels in published dataset. The data visualization tool Ordino (60) was used to compare the RNA expression levels of selected genes in The Cancer Cell Line Encyclopedia RNA-seq dataset (http://www.broadinstitute.org/ccle(22)).

Mutagenesis and selection with (S)-3 and (S)-4. 100.106 haploid HAP1 cells at $60 \%$ confluency were treated for $72 \mathrm{~h}$ with $0.3 \mathrm{mg} / \mathrm{mL}$ ethyl methanesulfonate (EMS, Sigma-Aldrich) directly added 
to the cell medium. After recovery, two $140 \mathrm{~mm}$ dishes at $10^{6}$ cells/dish were seeded from this mutagenized population and selected by treatment with $0.25 \mu \mathrm{M}$ DAC (S)-3 for $72 \mathrm{~h}$. After treatment, the medium was refreshed and, after 2-3 weeks, individual clones were isolated (DACR clones). To isolate AACR clones, the DACR clone \#A4 at early passage was mutagenized again $(0.3 \mathrm{mg} / \mathrm{ml} \mathrm{EMS} \mathrm{for} 72 \mathrm{~h})$. After recovery, the mutagenized DACR population was seeded into 140 $\mathrm{mm}$ dishes $\left(10^{6}\right.$ cells/dish) and selected by treatment with $10 \mu \mathrm{M}(\mathrm{S})-4$ for $72 \mathrm{~h}$. After treatment, the medium was refreshed and, after 2-3 weeks, individual clones were isolated (AACR clones).

RNA-seq. RNA-seq was performed at the GeT-PlaGe core facility, INRA Toulouse, from total RNA prepared with the RNeasy Plus Mini Kit (Qiagen) according to the manufacturer's instructions. RNA-seq libraries were prepared according to Illumina's protocols using the Illumina TruSeq Stranded mRNA sample prep kit. Briefly, mRNAs were selected using poly-dT beads. Then, RNAs were fragmented and adaptors ligated. Eleven cycles of PCR were applied for library amplification. Library quality was assessed using a Fragment Analyzer System (Agilent) and libraries were quantified by Q-PCR using the Kapa Library Quantification Kit (Roche). RNA-seq experiments were performed on an Illumina HiSeq3000 using a paired-end read length of 2x150 pb. RNA-seq data have been deposited on SRA (Bioproject IDs PRJNA668246 \& PRJNA668322).

RNA-Seq alignment and SNP prediction and filtering. Read quality was confirmed within the ng6 environment(61) using fastQC (http://www.bioinformatics.babraham.ac.uk/projects/fastqc/) and Burrows-Wheeler Aligner BWA (62) to search for contamination. The reads were cleaned with cutadapt v1.8.3 and aligned against hg38 reference human genome with STAR v2.5.2b (63). Expression levels were computed with featureCounts (64) using Ensembl annotation. Alignments were deduplicated with samtools rmdup and reads not uniquely mapped removed. Then GATK 524 v3.5 base quality score recalibration was applied (65). Indel realignment, SNP and INDEL discovery were performed with HaplotypeCaller using standard hard filtering parameters 
according to GATK best practices recommendations for RNAseq. Finally variants were annotated using snpEff v4.3t (66). A python script was used to select protein coding variants specific to resistant clones as compared to the parental HAP-1 (wild-type for DACR clones, and DACR\#A4 for AACR clones) with a minimal allele frequency of 0.9 and a depth greater than 10 reads. Among these variants, were selected the ones that resulted in frameshifts, mis- and non-sense mutations as compared to the reference human genome hg38. Cytoscape v3.2.0 (67) was used to identify genes found mutated in several clones and to generate a graphical overview.

Targeted sequencing of HSD17B11 cDNA from HAP-1 clones. Total RNAs were extracted from wild-type or DACR HAP-1 with the RNeasy Plus Mini Kit (Qiagen) according to the manufacturer's instructions. HSD17B11 cDNA was produced from these RNAs with the Superscript III First-Strand kit (Thermo Fisher Scientific) according to the manufacturer's instructions and using the HSD17B11-RNA-Rv primer. The resulting HSD17B11 cDNAs was amplified using the primer pair HSD17B11-RNA-Fw - HSD17B11-RNA-Rv and sequenced using the primers HSD17B11-SEQ-F and HSD17B11-SEQ-Rv (Eurofins Genomics).

Antibodies. For immunoblotting, horse-radish peroxidase-conjugated goat anti-mouse or antirabbit secondary antibodies (Jackson Immunoresearch Laboratories), or IRDye800CWconjugated donkey anti-mouse or anti-rabbit secondary antibodies (LI-COR Biosciences) were used, diluted at $1 / 10000$ in PBS $0.1 \%$ Tween-20. For immunofluorescence, AlexaFluor488- or AlexaFluor594-conjugated goat anti-mouse or anti-rabbit antibodies (Thermo Fisher Scientific) were used diluted at 1/1000 in blocking buffer. A list of primary antibodies used in this study, together with related information is provided in the table below (I.B., Immunoblotting; I.F., Immunofluorescence; * $\mathrm{RDH} 11$ antibody was used in immunofluorescence to check homogeneous RDH11 expression in complemented cells). 


\begin{tabular}{|c|c|c|c|c|c|c|}
\hline Target & Type & Clone/Ref. & Raised in & Source & $\begin{array}{l}\text { Dilution } \\
\text { for I.B. }\end{array}$ & $\begin{array}{l}\text { Dilution } \\
\text { for I.F. }\end{array}$ \\
\hline 53BP1 & Polyclonal & NB100-304 & Rabbit & $\begin{array}{l}\text { Novus } \\
\text { Biologicals }\end{array}$ & & $1 / 800$ \\
\hline$\beta$-Actin & Monoclonal & MAB1501 & Mouse & Chemicon & $1 / 20000$ & \\
\hline BRAT1 & Polyclonal & A300-728A & Rabbit & $\begin{array}{l}\text { Bethyl } \\
\text { laboratories }\end{array}$ & $1 / 700$ & \\
\hline COXIV & $\begin{array}{l}\text { Monoclonal } \\
\text { (AlexaFluor594 } \\
\text { conjugate) }\end{array}$ & 3E11 & Rabbit & Cell signaling & & $1 / 50$ \\
\hline GFP & Monoclonal & $7.1+13.1$ & Mouse & Roche & $1 / 2000$ & \\
\hline H2AX & Polyclonal & $a b 11175$ & Rabbit & Abcam & $1 / 4000$ & \\
\hline gH2AX & Monoclonal & JBW301 & Mouse & Millipore & & $1 / 1000$ \\
\hline HPGD & Polyclonal & HPA005679 & Rabbit & $\begin{array}{l}\text { Sigma- } \\
\text { Aldrich }\end{array}$ & $1 / 100$ & \\
\hline HSD17B11 & Polyclonal & 16303-1-AP & Rabbit & Proteintech & $1 / 250$ & \\
\hline HSP70 & Polyclonal & 10995-1-AP & Rabbit & Proteintech & $1 / 3000$ & \\
\hline IRE1 $\alpha-P h$ S724 & Polyclonal & NB100-2323SS & Rabbit & $\begin{array}{l}\text { Novus } \\
\text { Biologicals }\end{array}$ & $1 / 1000$ & \\
\hline Ku80 & Monoclonal & Clone 111 & Mouse & Thermo & $1 / 200$ & \\
\hline p21 WAF1/CIP1 & Polyclonal & sc-397-G / C-19 & Goat & Santa Cruz & $1 / 100$ & \\
\hline PARP-1 & Polyclonal & $\# 9542$ & Rabbit & $\begin{array}{l}\text { Cell Signaling } \\
\text { Tech. }\end{array}$ & $1 / 1000$ & \\
\hline PSMD2 & Polyclonal & A303-854A-T & Rabbit & $\begin{array}{l}\text { Bethyl } \\
\text { laboratories }\end{array}$ & $1 / 700$ & \\
\hline RDH11 & Monoclonal & $\begin{array}{l}\text { Clone 1B4 } \\
\text { GTX83716 }\end{array}$ & Mouse & GeneTex & $1 / 1000$ & $1 / 200^{*}$ \\
\hline SAFA & Monoclonal & $3 \mathrm{G} 6$ & Mouse & Santa Cruz & $1 / 100$ & \\
\hline Ubiquitin & Monoclonal & Clone VU-1 & Mouse & LifeSensors & $1 / 1000$ & \\
\hline
\end{tabular}

551 Live imaging. Pictures of living cells were acquired using an Olympus IX73 fluorescence

552 microscope fitted with a 40X objective (0.75NA UPlanFLN, Olympus) or a 20X 0.40 NA objective 553 (LCAChN 0.4NA, Olympus), a X-Cite Series 120Q lamp (Lumen dynamics), a DP26 camera 554 (Olympus) and using the adequate filters set. For time series, cells were seeded in glass-bottom 555 dishes (from MatTek or ibidi $\mu$ Slide) in phenol red-free Leibovitz's L-15 medium containing 10\% 556 FBS and pen./strep. For each time point, z-stacks were acquired using a Andor/Olympus 557 Yokogawa CSU-X1 confocal spinning disk fitted with 60X (UPLSAPO NA 1.35, Olympus) or 100X 558 (UPLSAPO NA 1.4, Olympus) objectives, a Andor iXon Life 888 EM-CCD camera and with 559 temperature and humidity control. The white scale bars on representative pictures represent 10 $560 \mu \mathrm{m}$.

561 Immunofluorescence. Cells were seeded on glass coverslips (\#1.5 thickness; 170 $\mu \mathrm{m}$, VWR).

562 At the end of the treatment, the cells were washed twice with PBS, fixed by a 15 min incubation 563 with 2\% paraformaldehyde (PFA) in PBS and washed three times. The cells were then 
permeabilized 5 min with $0.2 \%$ Triton $\mathrm{X}-100$ in PBS and washed three times with PBS. The coverslips were incubated 10 min in blocking buffer consisting in PBS 0.1\% Tween-20 (PBS-T) containing $5 \%$ bovine serum albumin (BSA). The coverslips were incubated for 75 min with the primary antibodies diluted in blocking buffer (mouse anti- $\gamma \mathrm{H} 2 \mathrm{AX}$ antibody at $1 / 1000$ and rabbit anti-53BP1 at 1/800), washed four times in PBS-T and then incubated 45 min with the secondary antibodies diluted in blocking buffer, washed four times in PBS-T and twice in PBS, incubated 15 min with $2 \mu \mathrm{g} / \mathrm{mL}$ DAPI (4',6-diamidino-2-phenylindole) in PBS, washed twice with PBS, dipped in double-distilled water and mounted in VectaShield on a glass slide. Pictures were acquired using an Olympus IX73 microscope fitted with a 40x UPlanFLN objective (Olympus), a X-Cite Series 120Q lamp (Lumen dynamics), a DP26 camera (Olympus) and using the adequate filters set. The white scale bars on each picture represent $10 \mu \mathrm{m}$.

Immunoblotting. For whole-cell extracts (WCE), cells were washed with cold PBS and scrapped in $75 \mu \mathrm{L}$ SDS-lysis buffer (120 mM Tris-HCl pH 6.8, 20\% glycerol, 4\% SDS), incubated 5 min at $95{ }^{\circ} \mathrm{C}$ and passed 10 times through a $25 \mathrm{G}$ needle. Measuring the absorbance at $280 \mathrm{~nm}$ with a Nanododrop spectrometer (Thermo Fisher Scientific) was used to evaluate protein concentration and, after adjustment with SDS-Lysis buffer, extracts were diluted by addition of equal volume of SDS-Loading Buffer (5 mM Tris $\mathrm{pH} 6.8,0.01 \%$ bromophenol blue, $0.2 \mathrm{M}$ dithiothreitol). Immunoblotting was performed with $25-50 \mu \mathrm{g}$ of WCE. Proteins were separated on gradient gels (BioRad 4-12\% TGX pre-cast gels) and transferred onto Protran $0.45 \mu \mathrm{m}$ nitrocellulose membranes (GE Healthcare). After transfer, membranes could be scanned with an infrared imager (Odyssey, LI-Cor Biosciences) to acquire the signal from AlexaFluor647 modified proteins. Homogeneous loading and transfer were checked by Ponceau S staining. When necessary, membranes were cut into horizontal strips to simultaneously probe for multiple proteins. For immunoblotting, membranes were blocked with PBS containing 5\% non-fat dry cow milk, washed and incubated for $1-2 \mathrm{~h}$ at room temperature or $16 \mathrm{~h}$ at $4{ }^{\circ} \mathrm{C}$ with primary antibodies diluted in 
PBS-T containing $1 \%$ bovine serum albumin (immunoglobulin- and lipid-free fraction $\vee$ BSA, Sigma-Aldrich). After extensive washes, membranes were probed $1 \mathrm{~h}$ at room temperature with adequate secondary antibodies coupled with horse-radish peroxidase (HRP) or with IRDye800CW. For HRP-conjugated secondary antibodies, signal acquisition was performed with a CCD camera (Chemidoc, BioRad) or using autoradiographic films (Blue Devil, Genesee Scientific) after incubation with peroxidase chemiluminescent substrates (BioRad Clarity ECL for CCD acquisition; Advansta WesternBright ECL for autoradiographic film exposure). For IRDye800CW-coupled secondary antibodies, membranes were scanned using an infrared imager (Odyssey, LI-Cor Biosciences).

Analysis by SDS-PAGE of proteins modified by DACs in cells. Sub-confluent $140 \mathrm{~mm}$ dishes, seeded two days before with U2OS or HAP-1 cells, were treated for $2 \mathrm{~h}$ with $2 \mu \mathrm{M}$ of DAC. At the end of treatment, cells were collected by trypsination and centrifugation ( $900 \mathrm{RPM}, 4^{\circ} \mathrm{C}, 5 \mathrm{~min}$ ). The cell pellet was washed with cold PBS before being lysed by sonication on ice (Vibracell, Bioblock Scientific, ten 2s-pulses, of amplitude 30 ) in $400 \mu \mathrm{L}$ of IPL buffer (20 mM Tris- $\mathrm{HCl} \mathrm{pH}$ 7.8, $1 \mathrm{mM}$ EDTA, $150 \mathrm{mM} \mathrm{NaCl}$, 0.5\% IGEPAL CA-630, HALT proteases and phosphatases inhibitor cocktail (Thermo Fisher Scientific)). A centrifugation (15000 RPM, $4{ }^{\circ} \mathrm{C}, 4 \mathrm{~min}$ ) was used to remove insoluble material and the supernatant was used for click reactions. The click reaction was performed by incubation at $20^{\circ} \mathrm{C}$ for $30 \mathrm{~h}$ of a mix containing $240 \mu \mathrm{g}$ of proteins (diluted in $10 \mu \mathrm{L}$ IPL buffer), $4 \mathrm{mM} \mathrm{CuSO}_{4}, 5 \mu \mathrm{M}$ azido-AlexaFluor647 and $10 \mathrm{mM}$ sodium ascorbate in IPD buffer $(20 \mathrm{mM}$ Tris-HCl pH 7.8, 1 mM EDTA, $150 \mathrm{mM} \mathrm{NaCl}$, 0.05\% IGEPAL CA-630, HALT inhibitors cocktail) to reach $80 \mu \mathrm{L} .20 \mu \mathrm{L}$ of 5 XLoading Buffer (300 mM Tris-HCl pH 6.8, 5\% SDS, $0.025 \%$ bromophenol blue, $15 \%$ glycerol, $250 \mathrm{mM}$ dithiothreitol) was added at the end of the reaction, followed by incubation at $95{ }^{\circ} \mathrm{C}$ for $5 \mathrm{~min} .24 \mathrm{\mu g}$ of proteins were separated on SDSPAGE gels (BioRad 4-15\% TGX pre-cast gels), followed by transfer onto Protran $0.45 \mu \mathrm{m}$ 
nitrocellulose membranes (GE Healthcare) which were scanned on an infrared imager (Odyssey, LI-COR Biosciences). A ponceau S staining was used to control for homogeneous loading.

Immunoprecipitation (IP). For IP, U2OS and HAP-1 parental or overexpressing GFP-tagged protein cell lines were seeded in $140 \mathrm{~mm}$ dishes two days before treatment. Sub-confluent cells were treated (or not) with the indicated molecules for $2 \mathrm{~h}$. At the end of treatment, cells were collected by trypsination and centrifugation (900 RPM, 5 min, $4{ }^{\circ} \mathrm{C}$ ). The cell pellet was washed with cold PBS before being lysed by sonication on ice (Vibracell, Bioblock Scientific, ten 2s-pulses, of amplitude 30) in $400 \mu \mathrm{L}$ of IPL buffer (20 mM Tris- $\mathrm{HCl} \mathrm{pH} 7.8,1 \mathrm{mM}$ EDTA, $150 \mathrm{mM} \mathrm{NaCl}$, 0.5\% IGEPAL CA-630, HALT proteases and phosphatases inhibitor cocktail (Thermo Fisher Scientific)). A centrifugation (15000 RPM, $4{ }^{\circ} \mathrm{C}, 4 \mathrm{~min}$ ) was used to remove insoluble material and the supernatant was used for IP. IP were performed by incubation of lysates $4 \mathrm{~h}$ at $4{ }^{\circ} \mathrm{C}$ on a rotating wheel with either $50 \mu \mathrm{L}$ of DynaBeads M-280 protein A magnetic beads (Thermo Fisher Scientific), pre-loaded with $8 \mu \mathrm{g}$ of rabbit control (Dako) or anti-PSMD2 (Bethyl Laboratories) antibodies, or with $50 \mu \mathrm{L}$ of anti-GFP magnetic beads (GFP-Trap, Chromotek). Each IP was done on $240 \mu \mathrm{g}$ of proteins diluted in $220 \mu \mathrm{L}$ of IPL buffer to which $480 \mu \mathrm{L}$ of IPD buffer was added (to dilute IGEPAL CA-630 to $~ 0.15 \%$ ). On-bead protein modification by DACones could be performed at that stage (see below). Then the beads were washed 3 times with high-salt IPW buffer $(20 \mathrm{mM}$ Tris-HCl pH 7.8, 1 mM EDTA, 500 mM NaCl, 0.05\% IGEPAL CA-630, HALT inhibitors cocktail) and once with IPD buffer (with $500 \mu \mathrm{L}$ for each wash).

On-bead protein modification by DACones. After IP, beads were washed twice in MoD buffer (10 mM phosphate $\mathrm{pH}$ 7.4, $2.7 \mathrm{mM} \mathrm{KCl}, 137 \mathrm{mM} \mathrm{NaCl}, 0.05 \%$ IGEPAL CA-630, HALT proteases and phosphatases inhibitor cocktail). Reactions with DACones were performed by incubating the beads 30 min at $30^{\circ} \mathrm{C}$ with vigorous intermittent shaking in $400 \mu \mathrm{L}$ of MoD buffer containing $1 \mu \mathrm{M}$ DAC (S)-9 or DACone 10. Beads were then washed with IPW buffer as described above and clicked as described below. 
On-bead click with azido-AlexaFluor647. Immunopurified proteins were clicked on beads by a 30 min-incubation at $20^{\circ} \mathrm{C}$ with vigorous intermittent shaking in $200 \mu \mathrm{L}$ of IPD buffer containing 4 $\mathrm{mM} \mathrm{CuSO}_{4}, 5 \mu \mathrm{M}$ azido-AlexaFluor647 and $10 \mathrm{mM}$ sodium ascorbate. The beads were washed with IPD buffer and resuspended in $20 \mu \mathrm{L}$ SDS-Lysis Buffer to which $20 \mu \mathrm{L}$ of SDS Loading buffer was added. Beads were incubated 5 min at $95^{\circ} \mathrm{C}$ in this solution and $20 \mu \mathrm{L}$ of supernatant was analyzed on gradient gels (BioRad 4-12\% TGX pre-cast gels). The modified proteins were detected with an infrared imager (Odyssey, LI-COR Bioscience) after transfer onto a nitrocellulose membrane (Protran, $45 \mu \mathrm{m}$ pores, GE Healthcare) and total proteins on the membrane were stained with Ponceau S.

In vitro protein modification by DACones for analysis by SDS-PAGE. FBS (Euromedex), bovine serum albumin (BSA, A-7030, Sigma-Aldrich), bovine carbonic anhydrase (CANH, C-3934, Sigma-Aldrich), Jack bean concanavalin A (ConcA, C-2010, Sigma-Aldrich), bovine betalactoglobulin (BLG, L-3908, Sigma-Aldrich) were resuspended at $2 \mathrm{mg} / \mathrm{mL}$ in $\mathrm{MoD}$ buffer. Reactions were performed for $40 \mathrm{~min}$ at $30^{\circ} \mathrm{C}$ in $50 \mu \mathrm{L}$ of $\mathrm{MoD}$ buffer containing $20 \mu \mathrm{g}$ of protein and $2 \mu \mathrm{M}$ of DAC or DACone. The reactions were then diluted to $75 \mu \mathrm{L}$ by sequential addition of IPD buffer, $\mathrm{CuSO}_{4}$, azido-AlexaFluor647 and sodium ascorbate to a final concentration of $4 \mathrm{mM}$,

$6544 \mu \mathrm{M}$ and $10 \mathrm{mM}$, respectively and incubated $30 \mathrm{~min}$ at $20^{\circ} \mathrm{C}$ with vigorous intermittent shaking. At that stage, unclicked azido-AlexaFluor647 could be removed using BioRad MicroBioSpin P-6 columns equilibrated with SDS-Lysis buffer and following manufacturer's instructions. Then, $8 \mu \mathrm{L}$

657 of the click reaction medium were supplemented with $12 \mu \mathrm{L}$ of SDS-Lysis buffer and $20 \mu \mathrm{L}$ of SDS 658 Loading buffer, incubated 5 min at $95^{\circ} \mathrm{C}$ and separated on gradient gels (BioRad $4-12 \%$ TGX pre659 cast gels). The modified proteins could be detected with an infrared imager (Odyssey, LI-COR 660 Biosciences) directly in the gel or after transfer onto a nitrocellulose membrane. Total proteins in 661 the gel or on the membrane were visualized using Coomassie (InstantBlue, Sigma-Aldrich, 662 scanned with the Odyssey or BioRad Chemidoc imagers) or Ponceau S staining, respectively. 
In vitro DAC bioactivation assays. HSD17B11 was immunopurified from UO2S KO HSD17B11 complemented either with HSD17B11-GFP wild-type or the S172L mutant. After extensive washes with a buffer containing $500 \mathrm{mM} \mathrm{NaCl}$, the magnetic beads were used as a source of HSD17B11 enzyme. HSD17B11 is a membrane-anchored protein (17) and its activity required maintaining a minimal $0.2 \%$ IGEPAL CA-630 concentration in all the buffers. In details, after IP, $30 \mu \mathrm{L}$ of beads were washed twice with MoD buffer and incubated $30 \mathrm{~min}$ at $30^{\circ} \mathrm{C}$ with vigorous intermittent shaking in $50 \mu \mathrm{L}$ of MoD buffer containing $0.2 \%$ IGEPAL CA-630, $1 \mathrm{mM} \beta-\mathrm{NAD}+, 2 \mu \mathrm{M}(S)$ - or $(R)$ 9 and $40 \mu \mathrm{g}$ of beta-lactoglobulin (BLG, L-3908, Sigma-Aldrich). The reactions were then diluted to $75 \mu \mathrm{L}$ by sequential addition of $\mathrm{MoD}$ buffer, $\mathrm{CuSO}_{4}$, azido-AlexaFluor647 and sodium ascorbate to final concentrations of $4 \mathrm{mM}, 3 \mu \mathrm{M}$ and $10 \mathrm{mM}$, respectively. The click reaction was performed by incubation $30 \mathrm{~min}$ at $20^{\circ} \mathrm{C}$ with vigorous intermittent shaking. $8 \mu \mathrm{L}$ of supernatant, containing the BLG, was supplemented with $12 \mu \mathrm{L}$ of SDS-Lysis and $20 \mu \mathrm{L}$ SDS Loading buffer, incubated 5 min at $95^{\circ} \mathrm{C}$ before analysis by SDS-PAGE and transfer onto a nitrocellulose membrane (Protran, $45 \mu \mathrm{m}$ pores, GE Healthcare). DACone adducts onto BLG were visualized by scanning the membrane with an infrared imager (Odyssey, LI-COR Biosciences) and total protein stained with Ponceau S.

MS analysis of entire $\beta$-lactoglobulin modified by DACone. Commercially available purified BLG (mixture of isoforms $A$ and $B$ ) was incubated for 40 min at $30^{\circ} \mathrm{C}$ in $40 \mu \mathrm{L}$ of MoD buffer containing $30 \mu \mathrm{M}$ BLG and $100 \mu \mathrm{M}$ DACone 10 (or the same volume of acetonitrile as control, $10 \%$ final concentration). Prior to MS analysis, unmodified and modified BLG samples were desalted in 200 mM ammonium acetate, $\mathrm{pH} 7$ using BioRad Micro Bio-Spin 6 devices and diluted to $\sim 4 \mu \mathrm{M}$ in $50 \%$ acetonitrile plus $0.2 \%$ formic acid final. Samples were analyzed on a SYNAPT G2-Si mass spectrometer (Waters, Manchester, UK) running in positive ion mode and coupled to an automated chip-based nano-electrospray source (Triversa Nanomate, Advion Biosciences, Ithaca, NY, USA). The voltage applied to the chip and the cone voltage were set to $1.6 \mathrm{kV}$ and 
688

689

690

691

692

693

694

695

696

697

698

699

700

701

702

703

704

705

706

707

708

709

710

711

712

$150 \mathrm{~V}$, respectively. The instrument was calibrated with a $2 \mathrm{mg} / \mathrm{mL}$ cesium iodide solution in $50 \%$ isopropanol. Raw data were acquired with MassLynx 4.1 (Waters, Manchester, UK) and deconvoluted with UniDec using the following parameters: $\mathrm{m} / \mathrm{z}$ range: $1,300-2,800 \mathrm{Th}$; subtract curved: 1; Gaussian smoothing: 10; bin every 1 Th; charge range: 5-15; mass range: 18,00019,000 Da; sample mass: every $1 \mathrm{Da}$; peak FWHM: 1 Th; peak detection range: $50 \mathrm{Da}$, and peak detection threshold: 0.1 . The mass spectrometry proteomics data have been deposited to the ProteomeXchange Consortium via the PRIDE (68) partner repository with the data set identifier PXD021955.

isoDTB-ABBP-based framework for assessing the proteome-wide selectivity of DACones.

Total cell extracts from U2OS cells were prepared by sonicating in $5 \mathrm{~mL}$ of PBS $0.1 \%$ IGEPAL CA-630 containing protease and phosphatase inhibitors (HALT cocktail, Pierce) a pellet of $1.5 \mathrm{~mL}$ of U2OS cells, collected by scrapping in cold PBS, followed by centrifugation 30 min at 15000 RPM at $4^{\circ} \mathrm{C}$. Protein concentration in the supernatant was evaluated using a Nanodrop device (Thermo Fisher Scientific) and the extracts diluted at $1 \mathrm{mg} / \mathrm{mL}$ with PBS containing protease and phosphatase inhibitors. $1 \mathrm{~mL}$ of extracts was incubated for $40 \mathrm{~min}$ at $30^{\circ} \mathrm{C}$ with $100 \mu \mathrm{M}$ of DACone 10 or 11 or acetonitrile (1\% final, solvent control). Proteins were then precipitated overnight at $20^{\circ} \mathrm{C}$ by addition of 4 volumes of cold acetone followed by centrifugation at $16000 \mathrm{~g}$ for $15 \mathrm{~min}$ at $4^{\circ} \mathrm{C}$. The precipitates were resuspended in $1 \mathrm{~mL}$ cold $\mathrm{MeOH}$ by sonification and centrifuged (10 min, $21100 \times \mathrm{g}, 4^{\circ} \mathrm{C}$ ). The supernatant was removed and the washing step with $\mathrm{MeOH}$ was repeated once. The pellets were dissolved in $1 \mathrm{~mL} 0.8 \%$ SDS in PBS by sonification. Duplicates were performed for each condition, one being clicked with the heavy isoDTB tag, the other one with the light tag. The click reaction, all subsequent experimental and analytical steps were performed as described (30). The data presented correspond to two independent experiments (Exp.1 and 2 in Supplementary Files 1 and 2). PSSM sequence logos were generated by analyzing the 10 amino acids surrounding the modified site using Seq2Logo (69). The mass 
spectrometry proteomics data have been deposited to the ProteomeXchange Consortium via the PRIDE (68) partner repository with the data set identifier PXD021955.

\section{Reaction of DACone with purified proteins for analysis of the absorbance spectrum.} Reactions were performed by incubation at $30^{\circ} \mathrm{C}$ for 40 min in $30 \mu \mathrm{L}$ of $\mathrm{MoD}$ buffer containing $115 \mu \mathrm{g}$ of protein (equivalent to $0.1 \mathrm{mM} \mathrm{BLG}$ and $0.035 \mathrm{mM} \mathrm{BSA}$ ) and $0.3 \mathrm{mM}$ of DAC or DACone. $2 \mu \mathrm{L}$ of each reaction were used to acquire a UV-visible (190-840 nm) absorbance spectrum on a Nanodrop device (Thermo Fisher Scientific).

\section{Reaction of DACones with NAG, NAC and NAK for analysis of the absorbance spectrum.}

Reactions were performed by incubation at $30{ }^{\circ} \mathrm{C}$ for $40 \mathrm{~min}$ in $40 \mu \mathrm{L}$ of a mixture containing 1 mM NAG, NAC or NAK and $1 \mathrm{mM}$ DACone 8 in $20 \mathrm{mM}$ phosphate buffer $(\mathrm{pH} 7.4)$ or $10 \mathrm{mM} \mathrm{KOH}$ (pH 10). A UV-visible (190-840 nm) absorbance spectrum for each reaction was acquired using a Nanodrop spectrometer (Thermo Fisher Scientific).

\section{NMR characterization of DACone reaction products with $N_{\alpha}$-Acetyl Lysine and $N$-Acetyl}

Cysteine. Reactions were performed by incubating at $30^{\circ} \mathrm{C}$ for 40 min a $300 \mu \mathrm{L}$ mixture containing $20 \mathrm{mM}$ DACone 8, $20 \mathrm{mM}$ NAC or $20 \mathrm{mM}$ NAK and $10 \mathrm{mM} \mathrm{KOH} \mathrm{(pH} \mathrm{10)} \mathrm{or} 20 \mathrm{mM}$ phosphate buffer ( $\mathrm{pH}$ 7.2). Each reaction was characterized by high-resolution mass spectrometry. After lyophilization, the samples were dissolved at a concentration of $10 \mathrm{mM}$ in PBS buffer $\mathrm{pH} 7.4$ with $10 \% \mathrm{D}_{2} \mathrm{O}$ containing DSS at $1 \mu \mathrm{M}$. All compounds were fully characterized by ${ }^{1} \mathrm{H}$ and ${ }^{13} \mathrm{C}$ NMR spectroscopy. NMR spectra were recorded at $298 \mathrm{~K}$ on Avance III HD 700 spectrometer $\left({ }^{1} \mathrm{H}\right.$ : 700.13 MHz, $\left.{ }^{13} \mathrm{C}: 176.04 \mathrm{MHz}\right) .{ }^{1} \mathrm{H}$ NMR spectra were recorded with water suppression. The correlation ${ }^{1} \mathrm{H}$ spectroscopy was acquired with the Bruker pulse sequence dipsiesgp using an excitation sculpting sequence for water suppression. The recycle delay was set to $1.5 \mathrm{~s} .{ }^{1} \mathrm{H}-{ }^{13} \mathrm{C}$ HSQC experiment (Bruker pulse sequence hsqcphpr) was recorded with carrier frequencies set to $4.7 \mathrm{ppm}\left({ }^{1} \mathrm{H}\right)$ and $85 \mathrm{ppm}\left({ }^{13} \mathrm{C}\right)$ and the spectral widths were set to $12 \mathrm{ppm}\left({ }^{1} \mathrm{H}\right)$ and $180 \mathrm{ppm}$ 
$737\left({ }^{13} \mathrm{C}\right)$. For this experiment, the recycle delay was set to $1 \mathrm{~s}$. Spectral data are provided in

\section{Supplementary Figure 8 and Supplementary Note 5.}

Identification of proteins modified by DAC (S)-9 in cells. Two $140 \mathrm{~mm}$ dishes, seeded with $2.5 \times 10^{6} \mathrm{U} 2 \mathrm{OS}$ cells two days before, were treated for $2 \mathrm{~h}$ with $2 \mu \mathrm{M}$ of DAC (S)-9 or $(R)-9$. At the end of treatment, cells were collected by trypsination and centrifugation ( $900 \mathrm{RPM}, 4{ }^{\circ} \mathrm{C}, 5 \mathrm{~min}$ ). The cell pellet was washed with cold PBS before being lysed by sonication on ice (Vibracell, Bioblock Scientific, ten 2s-pulses, of amplitude 30 ) in $240 \mu \mathrm{L}$ of IPL buffer (20 mM Tris- $\mathrm{HCl} \mathrm{pH}$ 7.8, $1 \mathrm{mM}$ EDTA, $150 \mathrm{mM} \mathrm{NaCl}$, 0.5\% IGEPAL CA-630, HALT proteases and phosphatases inhibitor cocktail (Thermo Fisher Scientific)). A centrifugation (15000 RPM, $4{ }^{\circ} \mathrm{C}, 4 \mathrm{~min}$ ) was used to remove insoluble material and the supernatant was used for click pull-down. A volume of lysate corresponding to $300 \mu \mathrm{g}$ of proteins was diluted to $500 \mu \mathrm{L}$ with IPD buffer ( $20 \mathrm{mM}$ Tris- $\mathrm{HCl} \mathrm{pH}$ 7.8, $1 \mathrm{mM}$ EDTA, $150 \mathrm{mM} \mathrm{NaCl}, 0.05 \%$ IGEPAL CA-630, HALT inhibitors cocktail) bringing IGEPAL CA-630 concentration to $0.2-0.25 \%$. The lysate was pre-cleared by incubation with $60 \mu \mathrm{L}$ streptavidin-coupled magnetic beads (Dynabeads M-280, Thermo Fisher Scientific) $1 \mathrm{~h}$ at $4{ }^{\circ} \mathrm{C}$ on a rotating wheel. Then $\mathrm{CuSO}_{4}$, biotin-azido and sodium ascorbate were added to the pre-cleared lysate at $4 \mathrm{mM}, 5 \mu \mathrm{M}$ and $10 \mathrm{mM}$ final concentration, respectively. The click-reaction was performed by incubation for $30 \mathrm{~min}$ at $20^{\circ} \mathrm{C}$ in the dark with vigorous intermittent shaking and the free biotin was removed from the clicked extracts using PD MiniTrap G-25 column (GE Healthcare) equilibrated with IPD buffer. The extracts were then complemented to $600 \mu \mathrm{L}$ with IPD buffer and incubated for $2 \mathrm{~h}$ at $4{ }^{\circ} \mathrm{C}$ on a rotating wheel with $60 \mu \mathrm{L}$ of streptavidin-coupled magnetic beads (Dynabeads M-280, Thermo Fisher Scientific). The beads, corresponding to the proteins associated to $(S)$ - or $(R)-\mathbf{9}$, were then washed extensively with high-salt IPW buffer (20 mM Tris$\mathrm{HCl} \mathrm{pH} \mathrm{7.8,} 1 \mathrm{mM}$ EDTA, $500 \mathrm{mM} \mathrm{NaCl}, 0.05 \%$ IGEPAL CA-630, HALT inhibitors cocktail), then with IPD buffer. For on-bead trypsic digestion, beads were washed twice with $50 \mathrm{mM}$ ammonium bicarbonate buffer, and then suspended in $7 \mathrm{M}$ urea and $25 \mathrm{mM}$ DTT (Sigma-Aldrich). After 60 
min under agitation (850 rpm) at room temperature, the samples were alkylated by incubation in $90 \mathrm{mM}$ iodoacetamide (Sigma-Aldrich) during $30 \mathrm{~min}$ in the dark. Samples were then washed twice as described above and submitted to overnight proteolysis in ammonium bicarbonate buffer containing $1 \mu \mathrm{g}$ of trypsin (Promega) per sample at $37^{\circ} \mathrm{C}$. The supernatants were collected, dried in speed-vac and resuspended with $2 \%$ acetonitrile and $0.05 \%$ trifluoroacetic acid (Sigma-Aldrich), for mass spectrometry analysis. The resulting peptides were analyzed with a NanoLC (Ultimate 3000 RSLCnano system Thermo Scientific) coupled to a LTQ Orbitrap Velos mass spectrometer (Thermo Fisher Scientific, Bremen, Germany). Raw MS files were processed with MaxQuant v1.5.2.8 software for database search with the Andromeda search engine and quantitative analysis. Data were searched against human entries in the Swissprot protein database. To perform relative quantification between proteins identified, we used the LFQ from the MaxQuant "protein group.txt" output. The experiment was repeated three times (exp. \#1, \#2 and \#3 in Supplementary File 3). The mass spectrometry proteomics data have been deposited to the ProteomeXchange Consortium via the PRIDE (68) partner repository with the data set identifier PXD021955. For each protein identified, the ratio (S)-9 vs (R)-9 conditions was computed (fold change, FC) and a t-test was used to select proteins reproductively enriched ( $F C>2$ and $p<0.05)$ in the (S)-9 vs (R)-9 condition. Cytoscape(67) was used to generate Figure 3B visual representation, in which the FC is color-coded, while the $-\log (p)$ was used to define protein box size (id large box means highly significant enrichment).

\section{Click-based imaging, GFP fluorescence and immunofluorescence imaging, pre-extraction.} Cells were seeded on \#1.5 glass coverslips (VWR) the day before the experiment. For labelling mitochondria with MitoTracker, MitoTracker Red CMXRos (Thermo Fisher Scientific) was added at $0.2 \mu \mathrm{M}$ in complete medium $30 \mathrm{~min}$ before the end of the treatments. To monitor the association of GFP-BRAT1 to insoluble compartments, cells were pre-extracted at the end of the treatment by a 2 min incubation on ice in cold PBS $0.1 \%$ Triton X-100 containing HALT proteases/phosphatase 
inhibitors cocktail. At the end of treatments or after pre-extraction, cells were washed twice with PBS, fixed 15 min with 2\% PFA in PBS and washed three times with PBS. Cells were permeabilized by incubation 8 min in PBS $0.2 \%$ Triton X-100 before being washed three times with PBS. When co-staining with antibody was performed, cells were incubated $10 \mathrm{~min}$ in IF blocking buffer (PBS-T 5\% BSA), before being incubated 75 min with AlexaFluor594-coupled antiCOXIV antibody diluted at 1:50 in IF blocking buffer. For co-staining of ER membranes with concanavalin A, fixed cells were incubated 30 min AlexaFluor488-coupled concanavalin A diluted at $100 \mu \mathrm{g} / \mathrm{mL}$ in blocking buffer. At the end of antibody/concanavalin staining, cells were washed four times, fixed for 15 min, washed three times with PBS and incubated in blocking buffer. Click with AlexaFluor488-azido or AlexaFluor594-azido was performed as described (70). At the end of the procedure, cells were washed four times with PBS-T, twice with PBS and incubated 15 min in PBS containing $2 \mu \mathrm{g} / \mathrm{mL}$ DAPI (Sigma-Aldrich). The coverslips were washed twice with PBS and mounted with VectaShield (Vector laboratories) on glass slides. Images were acquired on a Deltavision PersonalDV microscope (Applied Precision, 1024x1024 CoolSNAP HQ, z-stack of 0.2 $\mu \mathrm{m}$ interval) equipped with a 100x UPlanSApo/1.40 oil objective (Olympus) or with a Zeiss Elyra 7 3D Lattice SIM super-resolution microscope fitted with a $63 X$ objective (PLANAPO NA 1.4, Zeiss) and dual sCMOS cameras (pco.edge). Deconvolutions were then performed with SoftWoRx (Applied Precision) in conservative mode while 3D-SIM reconstruction were performed with Zen Black (Zeiss). The white scale bars on representative pictures represent $10 \mu \mathrm{m}$.

Flow cytometry. U2OS stably expressing the UPS fluorescent reporter Ub-G76V-YFP (38) were treated for $4 \mathrm{~h}$ with $20 \mu \mathrm{M}$ MG132 or $1 \mu \mathrm{M}(\mathrm{S})-3$. At the end of the treatment, cells were collected by trypsination, washed in PBS 1\% BSA and fixed by incubation at room temperature in $500 \mu \mathrm{L}$ of $2 \%$ PFA in PBS. Cells were washed with PBS $1 \%$ BSA and stored in the same buffer. A minimum of 30000 cells were analyzed on BD LSR II flow cytometer (Becton Dickinson). Data 
811 were analyzed and formatted using FlowJo v8.8.7. Untreated cells were used to define a gate to 812 identify the YFP positive cells in the treated conditions.

813 Synthesis. Synthesis and characterization of (S)-1(8), (R)-1(8), (R)-2(8), (S)-3(8), (R)-3(8), (S)814 4(8),(R,Sa)-5(19), (S, Sa)-5(19), (S)-6(20), (S)-9(33), (R)-9(33) have been described previously. 815 Enantiomeric (ee) and diasteromeric (de) excesses of aforementioned compounds are the 816 following: (S)-1 (90\% ee), (R)-1 (80\% ee), (R)-2 (80\% ee), (S)-3 (91\% ee), (R)-3 (93\% ee), (S)-4 817 (91\% ee), (R,Sa)-5 (98\% ee, 91\% de), (S, Sa)-5 (89\% ee, 74\% de), (S)-6 (89\% ee), (S)-9 (97\% 818 ee), $(R)-9 \quad(73 \%$ ee). Synthesis and characterization of new compounds is described in 819 Supplementary Note 4 and NMR spectra of all new compounds are provided in Supplementary $820 \quad$ Note 6.

821 Data availability. RNA-seq data, proteomics data and plasmids have been deposited on SRA, 822 PRIDE and Addgene, respectively. All other data are available upon request. 


\section{Acknowledgements}

826

827

828

829

830

831

832

We are grateful to the Genotoul bioinformatics platform Toulouse Occitanie and TRI-IPBS Imaging Core Facility, member of TRI-Genotoul, for providing help, computing and storage resources. The NMR spectra were recorded on spectrometers of the Integrated Screening Platform of Toulouse (PICT, IBISA). We thank Laurence Nieto (team C. Muller, IPBS, Toulouse, France), Raphaël Rodriguez (Institut Curie, Paris, France), Frédérique Fallone (Team C. Muller, IPBS, Toulouse, France), Frédéric Deschaseaux (STROMALab, Toulouse, France), Pierre Cordelier (CRCT, Toulouse, France), Robert A. Weinberg (Whitehead Institute, Boston, USA), Erik Snapp (HHMl's Janelia Research Campus, Ashburn, USA), Nico Dantuma (Karolinska Institutet, Stockholm, Sweden) for the generous gift of reagents; Antonio Peixoto \& Emmanuelle Näser (IPBS, Toulouse, France) for technical assistance; Andreas Merdes (CBI, Toulouse) for providing access to his microscope. We gratefully acknowledge Stephan A. Sieber and his group for their generous support. This study was funded by the grants IDEX Transversalité "Fishing Sponge" (2015 program) from Université Paul Sabatier; NPJA 20171206477 from "Fondation ARC", ANR-17-CE18-0002-01 from "Agence Nationale de la Recherche" and CAPES-COFECUB Ph-C $\mathrm{n}^{\circ}$ 883/17. The GeT and proteomics facilities received funding from "Investissements d'avenir" program as part of the "Genomic French Infrastructure" (grant ANR-10-INBS-09) and the "Proteomics French Infrastructure" (grant ANR-10-INBS-08 to O.B.-S.), respectively. The Proteomics facility received financial support from the "Fonds Européens de Développement Régional Toulouse Métropole and the Région Midi-Pyrénées" (to O.B.-S.). S.M.H. and P.R.A.Z. acknowledge funding by the Fonds der Chemischen Industrie through a Liebig Fellowship and a Ph.D. fellowship and by the TUM Junior Fellow Fund.

\section{Author contributions}


849 The authors contributed in the following manner: Conceptualization (S.Br. with inputs from P.C.,

850 P.D., J.M., E.J., Y.G., V.M., R.C., J.-B.I.), performed experiments (S.Br., P.D., J.M., P.R.A.Z., K.P., 851 R.H., M.M., R.-F.S., J.-B.I. with inputs from P.C., S.M.H., E.J., O.B.-S., O.B.), conceptualized and 852 designed small molecules synthesis (R.C., Y.G., V.M., V.B.-G., S.Ba., M.C.F.O. with inputs from 853 D.L., P.R.), performed small molecules synthesis (D.L., P.R., C.B., M.V.B.), performed 854 bioinformatics analysis (C.N., P.R.A.Z., S.M.H.), analyzed the data (S.Br., P.D., J.M., P.R.A.Z., 855 S.M.H., P.C., E.J., Y.G., R.C.), wrote the paper (S.Br with inputs from S.M.H., E.J., Y.G., R.C., 856 V.M., P.C., V.B.-G.).

857

858 Competing interests

859 A patent related to this work has been submitted. 


\section{References}

$8621 \quad$ Newman, D. J. \& Cragg, G. M. Natural Products as Sources of New Drugs over the

863

864

865

866

867

868

869

870

871

872

873

874

875

876

877

878

879

880

881

882

883

884

885

886

887

888

889

890

891

892

893

894

895

896

897

898

899

900

901

902

903

904

905

906

907
Nearly Four Decades from 01/1981 to 09/2019. J Nat Prod 83, 770-803, doi:10.1021/acs.jnatprod.9b01285 (2020).

2 Bergmann, W. \& Feeney, R. J. The isolation of a new thymine pentoside from sponges. $J$ Am Chem Soc 72, 2809-2810, doi:10.1021/ja01162a543 (1950).

3 Ellison, R. R. et al. Arabinosyl cytosine: a useful agent in the treatment of acute leukemia in adults. Blood 32, 507-523 (1968).

4 Seo, Y., Cho, K. W., Rho, J.-R., Shin, J. \& Sim, C. J. Petrocortynes and petrosiacetylenes, novel polyacetylenes from a sponge of the genus Petrosia. Tetrahedron 54, 447-462, doi:10.1016/S0040-4020(97)10290-3 (1998).

5 Ortega, M. J., Zubía, E., Carballo, J. L. \& Salvá, J. Fulvinol, a New Long-Chain Diacetylenic Metabolite from the Sponge Reniera fulva. J Nat Prod 59, 1069-1071, doi:10.1021/np960436l (1996).

6 Gunasekera, S. P. \& Faircloth, G. T. New acetylenic alcohols from the sponge Cribrochalina vasculum. J Org Chem 55, 6223-6225, doi:10.1021/jo00312a035 (1990).

$7 \quad$ Zovko, A. et al. Marine sponge Cribrochalina vasculum compounds activate intrinsic apoptotic signaling and inhibit growth factor signaling cascades in non-small cell lung carcinoma. Mol Cancer Ther 13, 2941-2954, doi:10.1158/1535-7163.MCT-14-0329 (2014).

8 El Arfaoui, D. et al. Identification of chiral alkenyl- and alkynylcarbinols as pharmacophores for potent cytotoxicity. ChemMedChem 8, 1779-1786, doi:10.1002/cmdc.201300230 (2013).

9 Listunov, D. et al. Extended structural modulation of bio-inspired chiral lipidic alkynylcarbinols as antitumor pharmacophores. Tetrahedron 71, 7920-7930, doi:10.1016/j.tet.2015.08.003 (2015).

10 Listunov, D. et al. From Natural to Artificial Antitumor Lipidic Alkynylcarbinols: Asymmetric Synthesis, Enzymatic Resolution, and Refined SARs. Synthesis 50, 31143130, doi:10.1055/s-0037-1610006 (2018).

11 Carette, J. E. et al. Haploid genetic screens in human cells identify host factors used by pathogens. Science 326, 1231-1235, doi:10.1126/science.1178955 (2009).

12 Wacker, S. A., Houghtaling, B. R., Elemento, O. \& Kapoor, T. M. Using transcriptome sequencing to identify mechanisms of drug action and resistance. Nat Chem Biol 8, 235237, doi:10.1038/nchembio.779 (2012).

13 Bossaert, M. et al. Transcription-associated topoisomerase 2alpha activity is a major effector of cytotoxicity induced by G-quadruplex ligands. eLife 10, doi:10.7554/eLife.65184 (2021).

14 Forment, J. V. et al. Genome-wide genetic screening with chemically mutagenized haploid embryonic stem cells. Nat Chem Biol 13, 12-14, doi:10.1038/nchembio.2226 (2017).

15 Brockmann, M. et al. Genetic wiring maps of single-cell protein states reveal an offswitch for GPCR signalling. Nature 546, 307-311, doi:10.1038/nature22376 (2017).

16 Brereton, P. et al. Pan1b (17betaHSD11)-enzymatic activity and distribution in the lung. Mol Cell Endocrinol 171, 111-117, doi:10.1016/s0303-7207(00)00417-2 (2001).

17 Horiguchi, Y., Araki, M. \& Motojima, K. Identification and characterization of the ER/lipid droplet-targeting sequence in 17beta-hydroxysteroid dehydrogenase type 11. Arch Biochem Biophys 479, 121-130, doi:10.1016/j.abb.2008.08.020 (2008). 
18 Filling, C. et al. Critical residues for structure and catalysis in short-chain dehydrogenases/reductases. J Biol Chem 277, 25677-25684, doi:10.1074/jbc.M202160200 (2002).

19 Listunov, D. et al. Methinylogation Approach in Chiral Pharmacophore Design: from Alkynyl- to Allenyl-carbinol Warheads against Tumor Cells. ChemMedChem 13, 17111722, doi:10.1002/cmdc.201800284 (2018).

20 Bourkhis, M. et al. Skeletal Optimization of Cytotoxic Lipidic Dialkynylcarbinols. ChemMedChem 13, 1124-1130, doi:10.1002/cmdc.201800118 (2018).

21 Grant, C. V. et al. CRISPR-Cas9 Genome-Wide Knockout Screen Identifies Mechanism of Selective Activity of Dehydrofalcarinol in Mesenchymal Stem-like Triple-Negative Breast Cancer Cells. J Nat Prod 83, 3080-3092, doi:10.1021/acs.jnatprod.0c00642 (2020).

22 Barretina, J. et al. The Cancer Cell Line Encyclopedia enables predictive modelling of anticancer drug sensitivity. Nature 483, 603-607, doi:10.1038/nature11003 (2012).

23 Worch, J. C., Stubbs, C. J., Price, M. J. \& Dove, A. P. Click Nucleophilic Conjugate Additions to Activated Alkynes: Exploring Thiol-yne, Amino-yne, and Hydroxyl-yne Reactions from (Bio)Organic to Polymer Chemistry. Chem Rev 121, 6744-6776, doi:10.1021/acs.chemrev.0c01076 (2021).

24 Tornoe, C. W., Christensen, C. \& Meldal, M. Peptidotriazoles on solid phase: $[1,2,3]-$ triazoles by regiospecific copper(i)-catalyzed 1,3-dipolar cycloadditions of terminal alkynes to azides. J Org Chem 67, 3057-3064, doi:10.1021/jo011148j (2002).

25 Rostovtsev, V. V., Green, L. G., Fokin, V. V. \& Sharpless, K. B. A stepwise huisgen cycloaddition process: copper(I)-catalyzed regioselective "ligation" of azides and terminal alkynes. Angew Chem Int Ed 41, 2596-2599, doi:10.1002/15213773(20020715)41:14<2596::AID-ANIE2596>3.0.CO;2-4 (2002).

26 Speers, A. E. \& Cravatt, B. F. Profiling enzyme activities in vivo using click chemistry methods. Chem Biol 11, 535-546, doi:10.1016/j.chembiol.2004.03.012 (2004).

27 Weerapana, E. et al. Quantitative reactivity profiling predicts functional cysteines in proteomes. Nature 468, 790-795, doi:10.1038/nature09472 (2010).

28 Backus, K. M. et al. Proteome-wide covalent ligand discovery in native biological systems. Nature 534, 570-574, doi:10.1038/nature18002 (2016).

29 Zanon, P. R. A., Lewald, L. \& Hacker, S. M. Isotopically Labeled Desthiobiotin Azide (isoDTB) Tags Enable Global Profiling of the Bacterial Cysteinome. Angew Chem Int Ed 59, 2829-2836, doi:10.1002/anie.201912075 (2020).

30 Zanon, P. R. A. et al. Profiling the Proteome-Wide Selectivity of Diverse Electrophiles. ChemRxiv, doi:10.33774/chemrxiv-2021-w7rss-v2 (2021).

31 Isom, D. G., Castaneda, C. A., Cannon, B. R. \& Garcia-Moreno, B. Large shifts in pKa values of lysine residues buried inside a protein. Proc Natl Acad Sci U S A 108, 52605265, doi:10.1073/pnas.1010750108 (2011).

32 Viedma-Poyatos, A. et al. Protein Lipoxidation: Basic Concepts and Emerging Roles. Antioxidants (Basel) 10, doi:10.3390/antiox10020295 (2021).

33 Listunov, D. et al. Fluorophore-tagged pharmacophores for antitumor cytotoxicity: Modified chiral lipidic dialkynylcarbinols for cell imaging. Bioorg Med Chem Lett 25, 46524656, doi:10.1016/j.bmcl.2015.08.029 (2015).

34 Vila, A. et al. Identification of protein targets of 4-hydroxynonenal using click chemistry for ex vivo biotinylation of azido and alkynyl derivatives. Chem Res Toxicol 21, 432-444, doi:10.1021/tx700347w (2008).

35 Larrieu, D., Britton, S., Demir, M., Rodriguez, R. \& Jackson, S. P. Chemical inhibition of NAT10 corrects defects of laminopathic cells. Science 344, 527-532, doi:344/6183/527 [pii] 
10.1126/science.1252651 (2014).

36 Blomen, V. A. et al. Gene essentiality and synthetic lethality in haploid human cells. Science 350, 1092-1096, doi:10.1126/science.aac7557 (2015).

37 Shi, Y. et al. Rpn1 provides adjacent receptor sites for substrate binding and deubiquitination by the proteasome. Science 351, doi:10.1126/science.aad9421 (2016).

38 Menendez-Benito, V., Verhoef, L. G., Masucci, M. G. \& Dantuma, N. P. Endoplasmic reticulum stress compromises the ubiquitin-proteasome system. Hum Mol Genet 14, 2787-2799, doi:10.1093/hmg/ddi312 (2005).

39 Mailand, N. et al. RNF8 ubiquitylates histones at DNA double-strand breaks and promotes assembly of repair proteins. Cell 131, 887-900, doi:10.1016/j.cell.2007.09.040 (2007).

40 Preissler, S. \& Ron, D. Early Events in the Endoplasmic Reticulum Unfolded Protein Response. Cold Spring Harb Perspect Biol 11, doi:10.1101/cshperspect.a033894 (2019).

41 Kavanagh, K. L., Jornvall, H., Persson, B. \& Oppermann, U. Medium- and short-chain dehydrogenase/reductase gene and protein families : the SDR superfamily: functional and structural diversity within a family of metabolic and regulatory enzymes. Cell Mol Life Sci 65, 3895-3906, doi:10.1007/s00018-008-8588-y (2008).

42 Kedishvili, N. Y. et al. Evidence that the human gene for prostate short-chain dehydrogenase/reductase (PSDR1) encodes a novel retinal reductase (RaIR1). J Biol Chem 277, 28909-28915, doi:10.1074/jbc.M202588200 (2002).

43 Haeseleer, F. et al. Dual-substrate specificity short chain retinol dehydrogenases from the vertebrate retina. J Biol Chem 277, 45537-45546, doi:10.1074/jbc.M208882200 (2002).

44 Tai, H. H., Cho, H., Tong, M. \& Ding, Y. NAD+-linked 15-hydroxyprostaglandin dehydrogenase: structure and biological functions. Current pharmaceutical design 12 , 955-962, doi:10.2174/138161206776055958 (2006).

45 Cui, C. et al. Total Synthesis and Target Identification of the Curcusone Diterpenes. J Am Chem Soc 143, 4379-4386, doi:10.1021/jacs.1c00557 (2021).

46 Shringarpure, R., Grune, T., Sitte, N. \& Davies, K. J. 4-Hydroxynonenal-modified amyloid-beta peptide inhibits the proteasome: possible importance in Alzheimer's disease. Cell Mol Life Sci 57, 1802-1809, doi:10.1007/pl00000660 (2000).

47 Bray, J. E., Marsden, B. D. \& Oppermann, U. The human short-chain dehydrogenase/reductase (SDR) superfamily: a bioinformatics summary. Chemicobiological interactions 178, 99-109, doi:10.1016/j.cbi.2008.10.058 (2009).

48 Chang, K. H. et al. A gain-of-function mutation in DHT synthesis in castration-resistant prostate cancer. Cell 154, 1074-1084, doi:10.1016/j.cell.2013.07.029 (2013).

49 Thomas, L. \& Sharifi, N. Germline HSD3B1 Genetics and Prostate Cancer Outcomes. Urology 145, 13-21, doi:10.1016/j.urology.2020.08.028 (2020).

50 Hearn, J. W. D. et al. HSD3B1 Genotype and Clinical Outcomes in Metastatic CastrationSensitive Prostate Cancer. JAMA Oncol 6, e196496, doi:10.1001/jamaoncol.2019.6496 (2020).

51 Kallberg, Y., Oppermann, U. \& Persson, B. Classification of the short-chain dehydrogenase/reductase superfamily using hidden Markov models. FEBS J 277, 23752386, doi:10.1111/j.1742-4658.2010.07656.x (2010).

52 Hacker, S. M. et al. Global profiling of lysine reactivity and ligandability in the human proteome. Nat Chem 9, 1181-1190, doi:10.1038/nchem.2826 (2017).

53 Abbasov, M. E. et al. A proteome-wide atlas of lysine-reactive chemistry. Nat Chem, doi:10.1038/s41557-021-00765-4 (2021).

54 Costantini, L. M. et al. A palette of fluorescent proteins optimized for diverse cellular environments. Nat Commun 6, 7670, doi:10.1038/ncomms8670 (2015). 
1008

1009

1010

1011

1012

1013

1014

1015

1016

1017

1018

1019

1020

1021

1022

1023

1024

1025

1026

1027

1028

1029

1030

1031

1032

1033

1034

1035

1036

1037

1038

1039

1040

1041

1042

1043

1044

1045

1046

1047

1048

1049

1050

1051
55 Olenych, S. G., Claxton, N. S., Ottenberg, G. K. \& Davidson, M. W. The fluorescent protein color palette. Curr Protoc Cell Biol Chapter 21, Unit 21 25, doi:10.1002/0471143030.cb2105s36 (2007).

56 Britton, S. et al. DNA damage triggers SAF-A and RNA biogenesis factors exclusion from chromatin coupled to R-loops removal. Nucleic Acids Res 42, 9047-9062, doi:10.1093/nar/gku601 (2014).

57 Britton, S., Coates, J. \& Jackson, S. P. A new method for high-resolution imaging of Ku foci to decipher mechanisms of DNA double-strand break repair. J Cell Biol 202, 579595, doi:10.1083/jcb.201303073 (2013).

58 Carette, J. E. et al. Ebola virus entry requires the cholesterol transporter Niemann-Pick C1. Nature 477, 340-343, doi:10.1038/nature10348 (2011).

59 Slaymaker, I. M. et al. Rationally engineered Cas9 nucleases with improved specificity. Science 351, 84-88, doi:10.1126/science.aad5227 (2016).

60 Streit, M. et al. Ordino: a visual cancer analysis tool for ranking and exploring genes, cell lines and tissue samples. Bioinformatics 35, 3140-3142, doi:10.1093/bioinformatics/btz009 (2019).

61 Mariette, J. et al. NG6: Integrated next generation sequencing storage and processing environment. BMC Genomics 13, 462, doi:10.1186/1471-2164-13-462 (2012).

$62 \mathrm{Li}, \mathrm{H}$. \& Durbin, R. Fast and accurate short read alignment with Burrows-Wheeler transform. Bioinformatics 25, 1754-1760, doi:10.1093/bioinformatics/btp324 (2009).

63 Dobin, A. et al. STAR: ultrafast universal RNA-seq aligner. Bioinformatics 29, 15-21, doi:10.1093/bioinformatics/bts635 (2013).

64 Liao, Y., Smyth, G. K. \& Shi, W. featureCounts: an efficient general purpose program for assigning sequence reads to genomic features. Bioinformatics 30, 923-930,

doi:10.1093/bioinformatics/btt656 (2014).

65 McKenna, A. et al. The Genome Analysis Toolkit: a MapReduce framework for analyzing next-generation DNA sequencing data. Genome Res 20, 1297-1303, doi:10.1101/gr.107524.110 (2010).

66 Cingolani, P. et al. A program for annotating and predicting the effects of single nucleotide polymorphisms, SnpEff: SNPs in the genome of Drosophila melanogaster strain w1118; iso-2; iso-3. Fly (Austin) 6, 80-92, doi:10.4161/fly.19695 (2012).

67 Shannon, P. et al. Cytoscape: a software environment for integrated models of biomolecular interaction networks. Genome Res 13, 2498-2504, doi:10.1101/gr.1239303 (2003).

68 Perez-Riverol, Y. et al. The PRIDE database and related tools and resources in 2019: improving support for quantification data. Nucleic Acids Res 47, D442-D450, doi:10.1093/nar/gky1106 (2019).

69 Thomsen, M. C. \& Nielsen, M. Seq2Logo: a method for construction and visualization of amino acid binding motifs and sequence profiles including sequence weighting, pseudo counts and two-sided representation of amino acid enrichment and depletion. Nucleic Acids Res 40, W281-287, doi:10.1093/nar/gks469 (2012).

70 Rozie, A. et al. Alkyne-Tagged Analogue of Jaspine B: New Tool for Identifying Jaspine B Mode of Action. Chembiochem 19, 2438-2442, doi:10.1002/cbic.201800496 (2018). 


\section{Figure 1}

A<smiles>C#CCCCC#CC#CC(O)C#C</smiles>

D

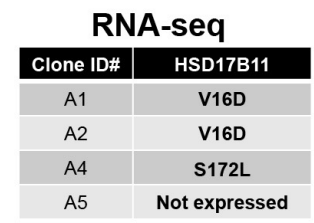

DACR\#A5 +

Plasmid: GFP HSD17B11-GFP

Clone ID: $\overline{G 1 ~ G 2} \overline{W 1 W 2} \overline{S 1 ~ S 2}$

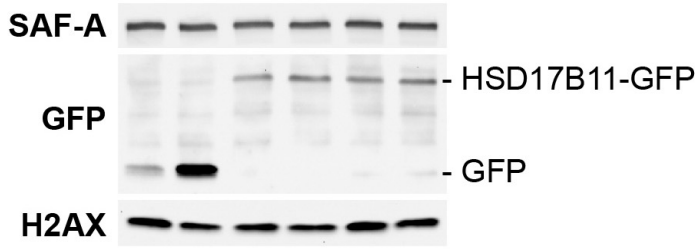



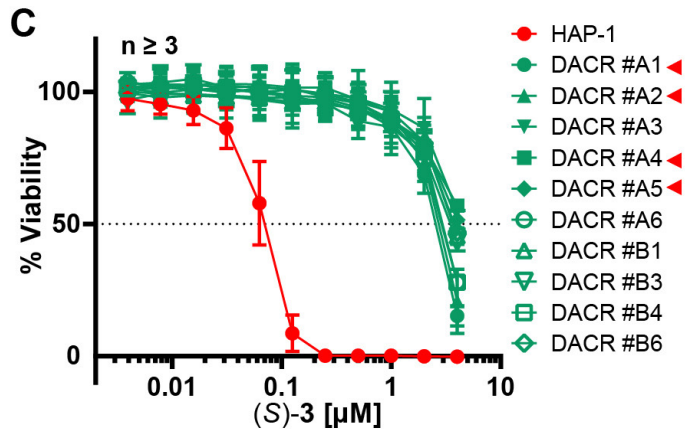

E

\begin{tabular}{|c|c|}
\hline Clone ID\# & HSD17B11 \\
\hline A3 & R31* \\
\hline A6 & G45R \\
\hline B1 & L14P \\
\hline B3 & Not amplified \\
\hline B4 & G45R \\
\hline B6 & A147V \\
\hline
\end{tabular}

Targ

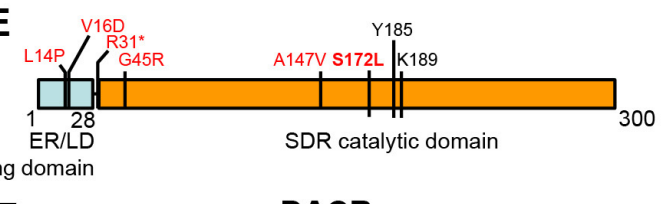

$\mathbf{F}$ WT $\overline{A 1}$ A2 A3 A4 A5 A6 B1 B3 B4 B6 WT

HSD17B11
H DACR\#A5 +

GFP $-\#$ E1 \# \# 2 HSD17B11-WT - \#W1 $\theta$ \#W2 HSD17B11-S172L * \#S1 7 \#S2

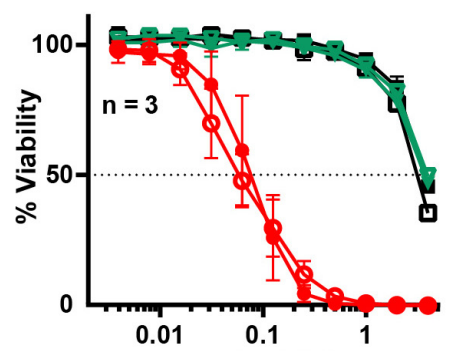

$(S)-3[\mu \mathrm{M}]$ 
1054 Figure 1: HSD17B11 is necessary for DAC (S)-3 cytotoxic activity. A. DAC (S)-3 and $(R)-3$ 1055 structures. B. Cell viability analysis of HAP-1 or U2OS cells treated for $72 \mathrm{~h}$ with the indicated 1056 concentrations of (S)- or (R)-3. C. Cell viability analysis of individual DAC-resistant clones or wild1057 type HAP-1 treated for $72 \mathrm{~h}$ with the indicated concentrations of (S)-3. D. List of mutations 1058 identified by RNA-seq or targeted sequencing of HSD17B11 in individual DAC-resistant clones. 1059 E. Schematic representation of HSD17B11 functional domains. The positions of the identified 1060 mutations are indicated in red. The Y185, K189 (indicated in black) and S172 amino acids are 1061 critical for catalysis. F. Analysis by immunoblotting of HSD17B11 levels in wild-type HAP-1 and 1062 DAC-resistant clones. Ku80 was used as a loading control. The black arrow indicates HSD17B11 1063 position. G. Analysis by immunoblotting of HSD17B11-GFP levels in individual clones of DAC1064 resistant clone A5 complemented with GFP, wild-type or S172L mutant HSD17B11-GFP. SAF-A 1065 and total H2AX were used as loading controls. H. Cell viability analysis of individual clones of 1066 DAC-resistant clone A5 complemented with GFP, wild-type or S172L mutant HSD17B11-GFP 1067 treated for $72 \mathrm{~h}$ with the indicated concentrations of (S)-3. 


\section{Figure 2}

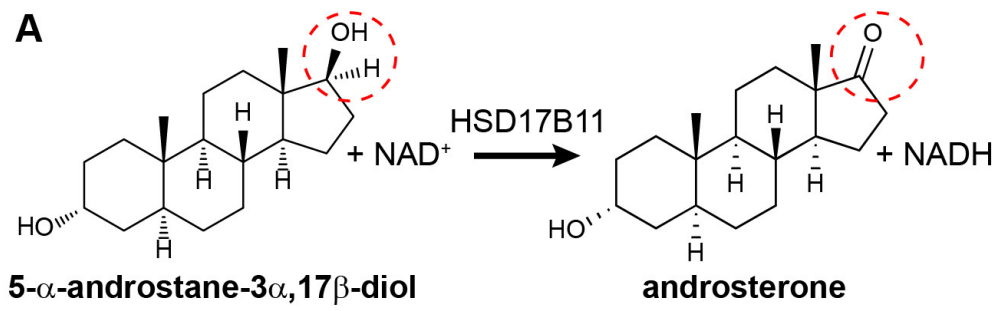

B<smiles></smiles><smiles>C#CC(=O)O</smiles><smiles>C#CC(=O)O</smiles><smiles>C#CC(O)C#[As]</smiles><smiles></smiles><smiles>C#CC(=O)C#C</smiles><smiles>C#CC(O)C#C</smiles>

\section{E}

G

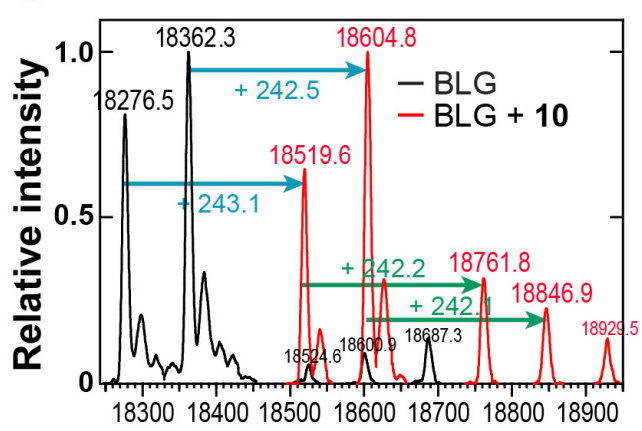

Mass (Da)

D

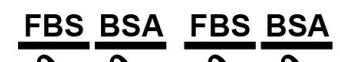

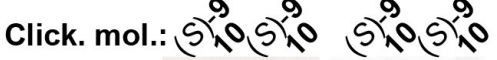

MW 180 -

(kDa) 130 -

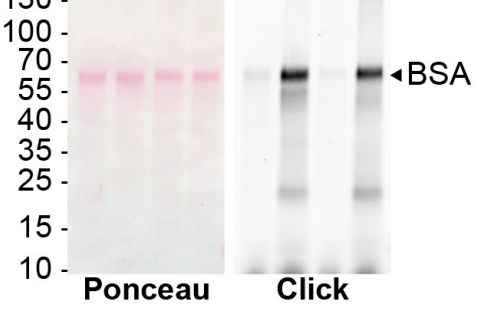

1069
$\mathrm{IC}_{50}(\mathrm{nM}) \mathbf{1 ~ h}$ in PBS $\left(+\mathrm{Ca}^{2+} / \mathrm{Mg}^{2+}\right)$

991 DAC $(S)-3$

2,439 DACone 7 U2OS

328 DACone 8

27,970 $\odot$ DAC (S)-3

1,689 DACone 7 U2OS

\begin{tabular}{ll|l}
308 & $\odot$. DACone 8 & $\Delta$ HSD17B11
\end{tabular}

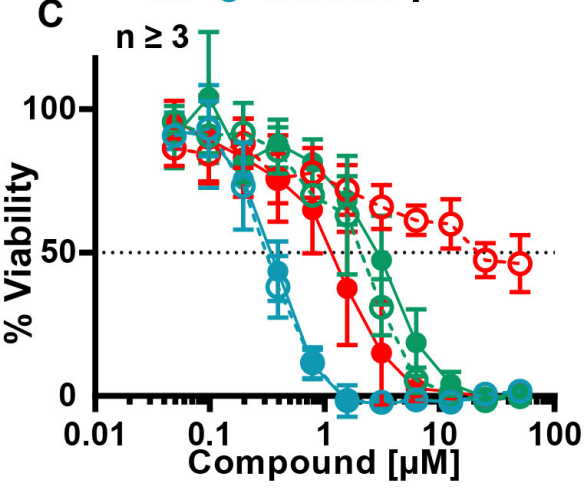

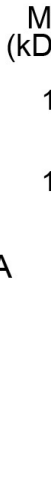

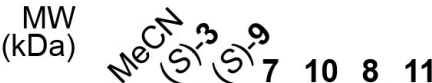

$108=$

198 :- - - - B - BSA

$15-\quad$ Click

$10-$

$15-m-m-m$ BLG

H

. 80 isoDTB-ABPP analysis
$\mathbf{F}$

HSD17B11

Click. DAC 9: $(S)(S)(R)(S)(R)$

BLG: - + + + +

Click

Ponceau $-15$

- 10 (121 modified sites in total)

11 (129 modified sites in total) 
1070 Figure 2: DACones are protein reactive species. A. Reaction catalyzed by HSD17B11. B.

1071 Clickable DACs and DACones used in the study. C. Viability analysis of U2OS cells treated in 1072 PBS for $1 \mathrm{~h}$ with (S)-3 or DACones and incubated for an additional $72 \mathrm{~h}$ after drug washout. D. 1073 FBS or purified BSA were incubated 40 min at $30^{\circ} \mathrm{C}$ with clickable DAC (S)-9 or clickable DACone 1074 10. After reaction, CuAAC was used to ligate an azido-AlexaFluor647 to clickable molecules. 1075 Modified proteins were detected by scanning membrane fluorescence after SDS-PAGE and 1076 transfer. Ponceau S stains total proteins. E. BSA or BLG were incubated with the indicated DACs 1077 or DACones, as in D. After reaction, modified proteins were detected as in $\mathbf{D}$. Coomassie stains 1078 total proteins. F. WT or S172L HSD17B11-GFP were immunoprecipitated from complemented 1079 U2OS KO HSD17B11 cells and incubated with clickable DAC 9 and BLG. After reaction modified 1080 proteins were detected as in d. G. Analysis by direct-infusion mass spectrometry of purified BLG 1081 (mixture of isoform A and B) modified or not by DACone 10. Cyan and green arrows indicate the 1082 formation of a first and second adduct, respectively. H. \% of each amino acid detected as modified 1083 by DACones $\mathbf{1 0}$ or $\mathbf{1 1}$ in U2OS extracts as determined using a isoDTB-ABPP-based framework. 1084 I. Proposed reactions of DACones with cysteine and lysine side chains in proteins. 
Figure 3
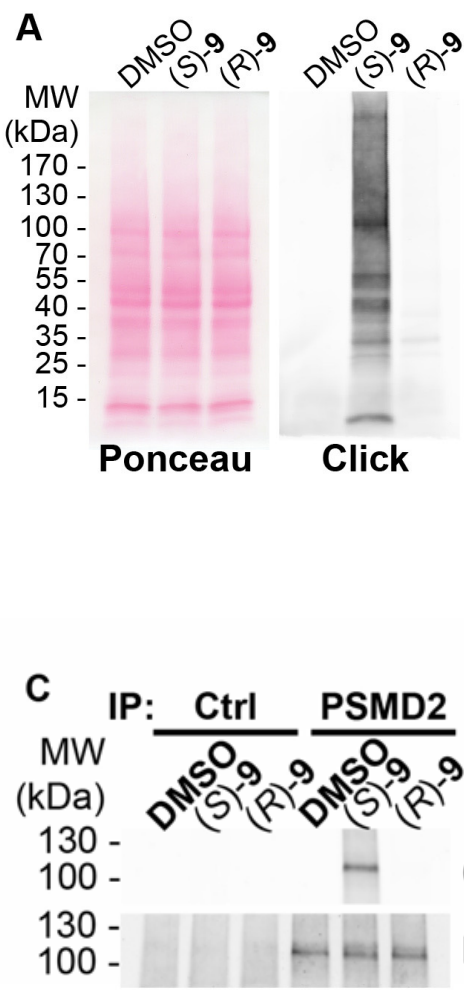

$\mathrm{E}$
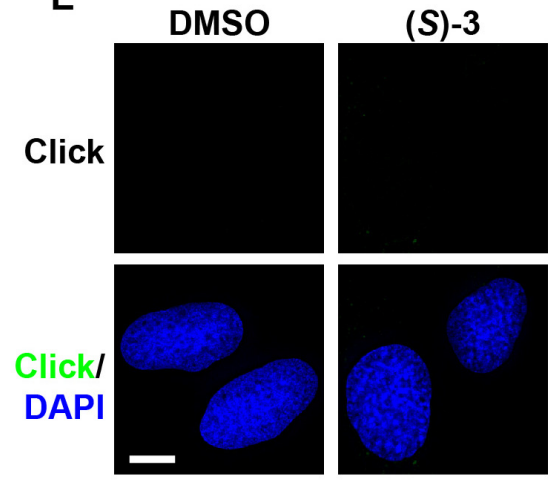

Click
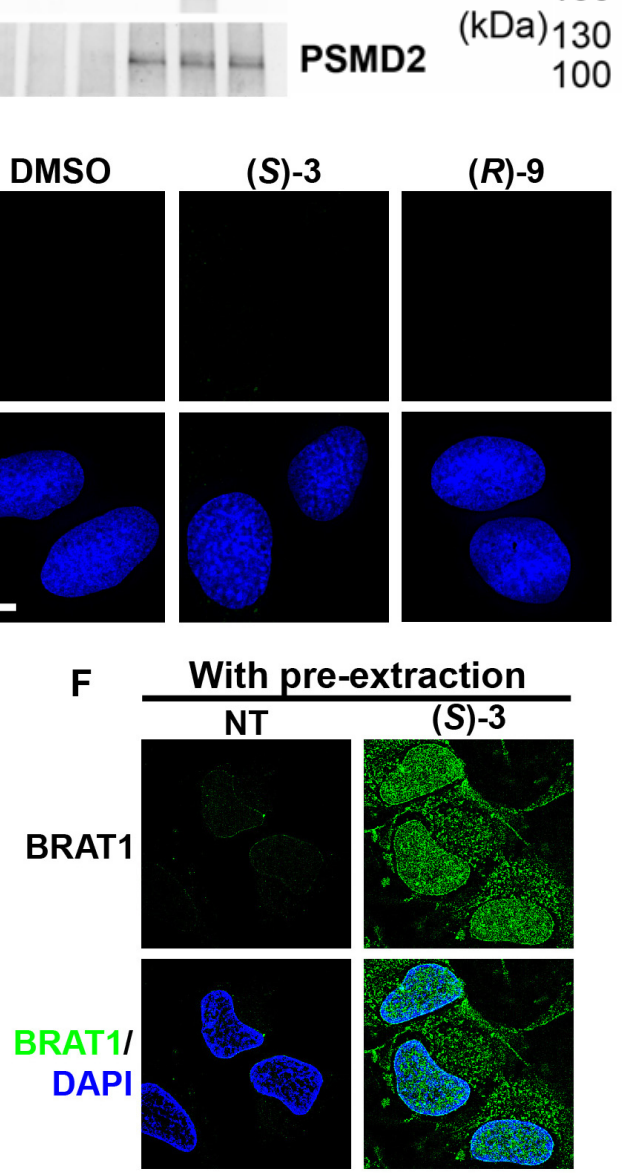

1086
B
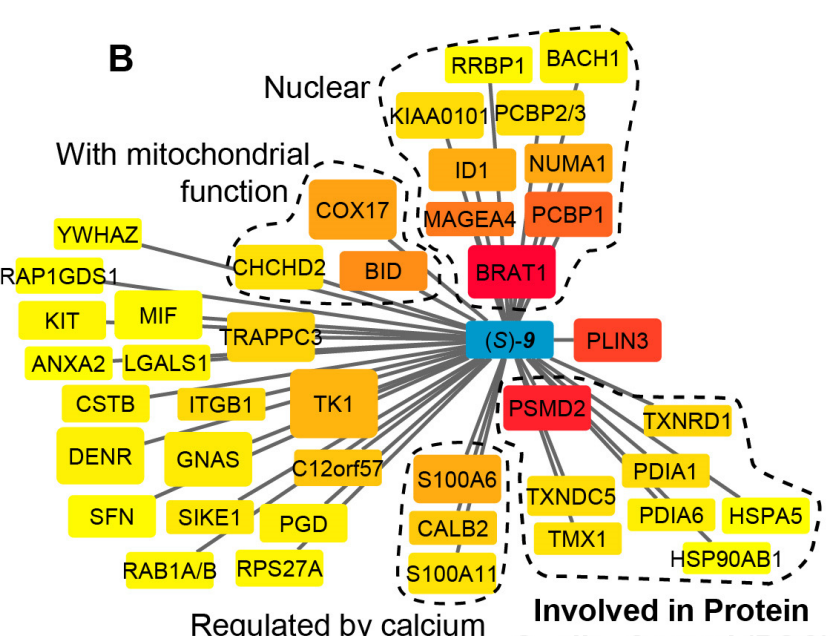

Regulated by calcium

2x FC $80 x$

D

IP APSMD2

HAP-1: WT DACR DACR

(S)-9: $\frac{W}{-+} \frac{\mathrm{A} 1}{-+} \frac{\mathrm{A} 4}{-+}$ MW100 -

Click

(kDa) 130 100 -

PSMD2 

cellular membranes. A. U2OS cells were incubated for $2 \mathrm{~h}$ with $2 \mu \mathrm{M}(S)$ - or $(R)-9$, proteins were extracted and DAC-modified proteins were detected by CuAAC-mediated ligation of azidoAlexaFluor-647 to clickable molecules, separation by SDS-PAGE, transfer to a membrane which was scanned for fluorescence. B. Landscape of proteins modified in U2OS cells by clickable DAC (S)-9 computed from 3 independent experiments. Fold enrichment (FC) as compared to the clickable (R)-9 is computed and color-coded as depicted. Box size corresponds to $-\log (p)$ computed as described in the materials and methods section.

C. PSMD2 or control 1095 immunoprecipitations (Ctrl) were performed from extracts of U2OS cells treated $2 \mathrm{~h}$ with $2 \mu \mathrm{M}$ clickable DAC (S)- or (R)-9. DAC-modified proteins were detected by CuAAC-mediated ligation of azido-AlexaFluor-647 to clickable molecules, separation by SDS-PAGE, transfer to a membrane, which was scanned for fluorescence. PSMD2 was subsequently visualized by immunoblotting. PSMD2 immunoprecipitations were performed from extracts of wild-type or DAC-resistant HAP-1 cells treated or not for $2 \mathrm{~h}$ with $2 \mu \mathrm{M}$ clickable DAC (S)-9. DAC-modified proteins were detected by CuAAC-mediated ligation as in (c) PSMD2 was subsequently visualized by immunoblotting. $\mathrm{E}$. U2OS cells were treated $2 \mathrm{~h}$ with $0.5 \mu \mathrm{M}$ DAC, fixed, permeabilized, and clickable molecules were

1103 detected by click with AlexaFluor488 azide. F. U2OS expressing GFP-BRAT1 were treated $2 \mathrm{~h}$ with $1 \mu \mathrm{M}(S)-3$, pre-extracted, fixed and processed for analysis by fluorescence microscopy. 
Figure 4

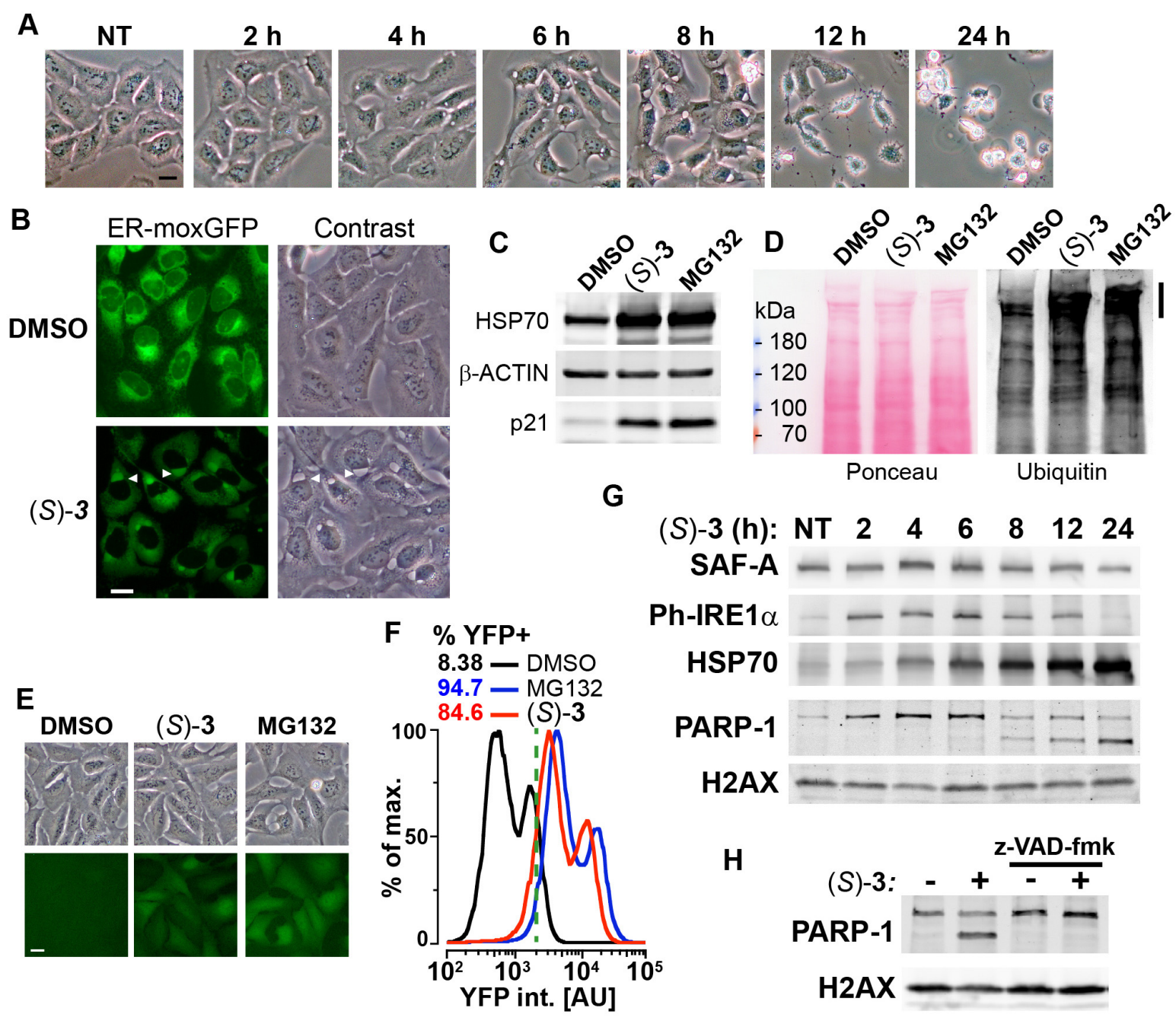


1107 Figure 4: DAC (S)-3 triggers ER-stress, proteasome inhibition and apoptosis. A. U2OS

1108 stably co-expressing a GFP variant addressed and retained in the endoplasmic reticulum were 1109 treated with $1 \mu \mathrm{M}(S)-3$ and monitored by live imaging. Representative pictures of U2OS cells 1110 either untreated (NT) or treated with $1 \mu \mathrm{M}(\mathrm{S})-\mathbf{3}$ for the indicated time. B. Representative pictures 1111 of U2OS with stably GFP-labeled endoplasmic reticulum and either untreated or treated for $8 \mathrm{~h}$ 1112 with $1 \mu \mathrm{M}(\mathrm{S})-3$. C. Immunoblotting of extracts from U2OS untreated or treated with $1 \mu \mathrm{M}(S)-3$ or $111320 \mu \mathrm{M}$ MG132 for 8 h. D. Immunoblotting of ubiquitin in extracts from U2OS untreated or treated 1114 with $1 \mu \mathrm{M}(S)-3$ or $20 \mu \mathrm{M}$ MG132 for $2 \mathrm{~h}$. High molecular weight ubiquitin conjugates are indicated 1115 by a vertical bar on the right. E. Representative pictures of U2OS stably expressing Ub-G76V1116 YFP and either untreated or treated for $4 \mathrm{~h}$ with $1 \mu \mathrm{M}(\mathrm{S})-3$ or $20 \mu \mathrm{M}$ MG132. F. Analysis of YFP 1117 fluorescence by flow cytometry of U2OS Ub-G76V-YFP treated as described in E. \% of cells 1118 scored as positives using the vertical green bar as a threshold are indicated. G. Immunoblotting 1119 using extracts from U2OS cells treated with $1 \mu \mathrm{M}(S)-3$ for increasing times, indicated in hours. $\mathbf{H}$. 1120 Immunoblotting using extracts from U2OS cells treated with $1 \mu \mathrm{M}(\mathrm{S})-3$ for $12 \mathrm{~h}$ with or without 50 $1121 \mu \mathrm{M} z-\mathrm{VAD}-\mathrm{fmk}$. 


\section{Figure 5}
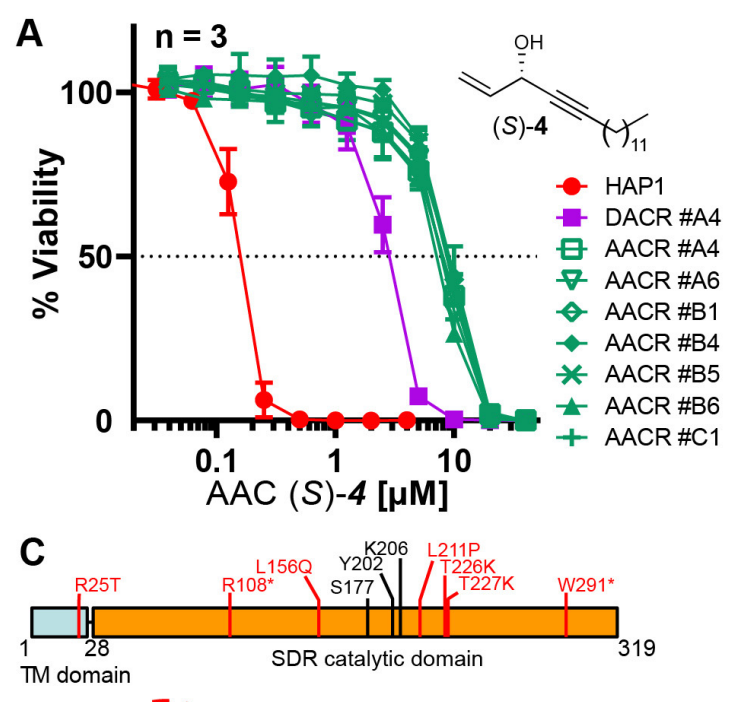

E
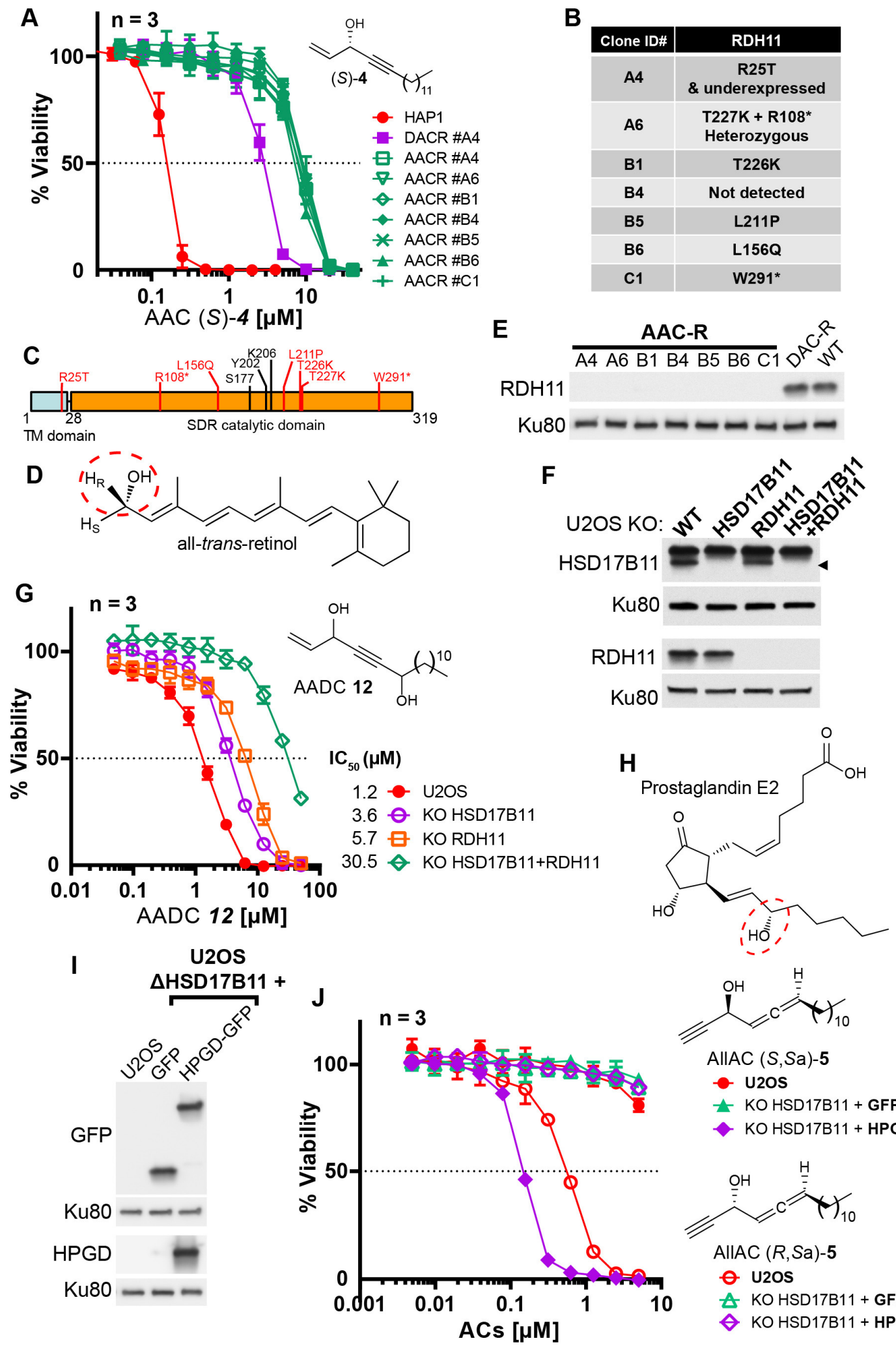

AllAC ( $S, S a)-5$

- U2OS

t KO HSD17B11 + GFP

- KO HSD17B11 + HPGD<smiles>C#C[C@H](O)C=C=CCC(C)C</smiles>

$\operatorname{AllAC}(R, S a)-5$

○ U2OS

A KO HSD17B11 + GFP

$\diamond \mathrm{KOHSD17B11}+\mathrm{HPGD}$ 
1124 Figure 5: Bioactivation of other lipidic alkynylcarbinols by specific SDRs. A. Cell viability 1125 analysis of wild-type HAP-1, DACR clone A4 and AACR clones treated with AAC (S)-4. B. List of 1126 mutations identified on RDH11 by RNA-seq of individual AACR clones. C. Schematic 1127 representation of $\mathrm{RDH} 11$ with, in red, the positions of the mutations identified and, in black, the 1128 three amino acids critical for catalysis. TM = single-pass transmembrane domain. D. Structure of 1129 all-trans-retinol, a substrate for RDH11. E. Analysis by immunoblotting of RDH11 levels in wild1130 type HAP-1, in DACR clone A4 and in the different AACR clones. F. Analysis by immunoblotting 1131 of RDH11 and HSD17B11 levels in wild-type U2OS or clones inactivated for either HSD17B11, 1132 RDH11 or both. G. Cell viability analysis of wild-type U2OS or U2OS clones inactivated for 1133 HSD17B11, RDH11, or both and treated with AADC 12. H. Structure of prostaglandin E2, a 1134 substrate of HPGD. I. Analysis by immunoblotting of GFP and HPGD levels in WT U2OS or U2OS 1135 KO HSD17B11 stably complemented with GFP or HPGD-GFP. J. Cell viability analysis of U2OS 1136 or U2OS inactivated for HSD17B11, stably complemented with either HSD17B11-GFP or HPGD1137 GFP and treated for $72 \mathrm{~h}$ with $\operatorname{AllAC}(\mathrm{S}, \mathrm{Sa})$ - or $(R, \mathrm{Sa})-\mathbf{5}$. 


\section{Figure 6}

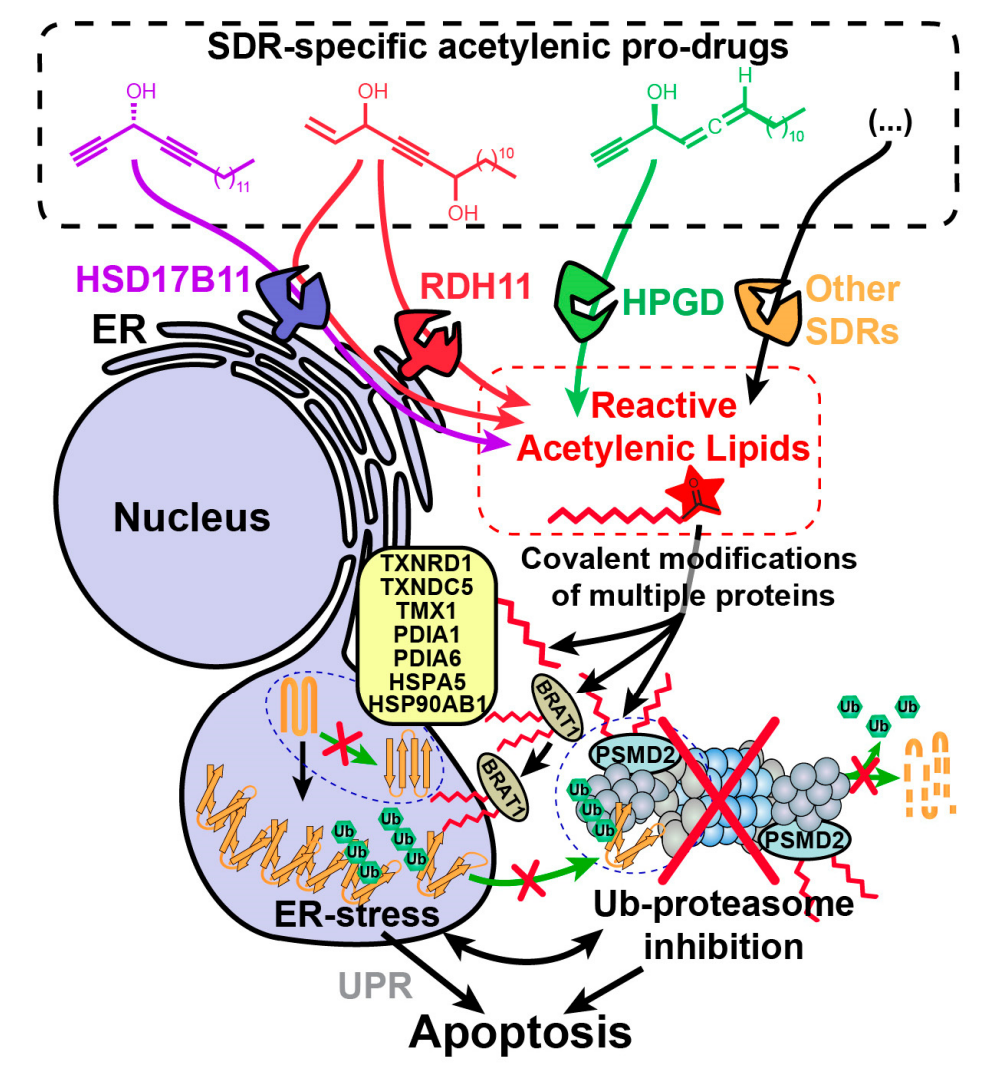

1141 Figure 6: Model depicting the stereospecific bioactivation of alkynylcarbinol-containing

1142 compounds by specific SDRs into cytotoxic protein-reactive species. The protein reactive species 1143 generated upon bioactivation modify several proteins including the essential 26S proteasome 1144 subunit PSMD2, thereby triggering Ub-proteasome system (UPS) inhibition, ER-stress, activation of the Unfolded Protein Response (UPR) and cell death mediated by apoptosis. 


\section{Graphical abstract}

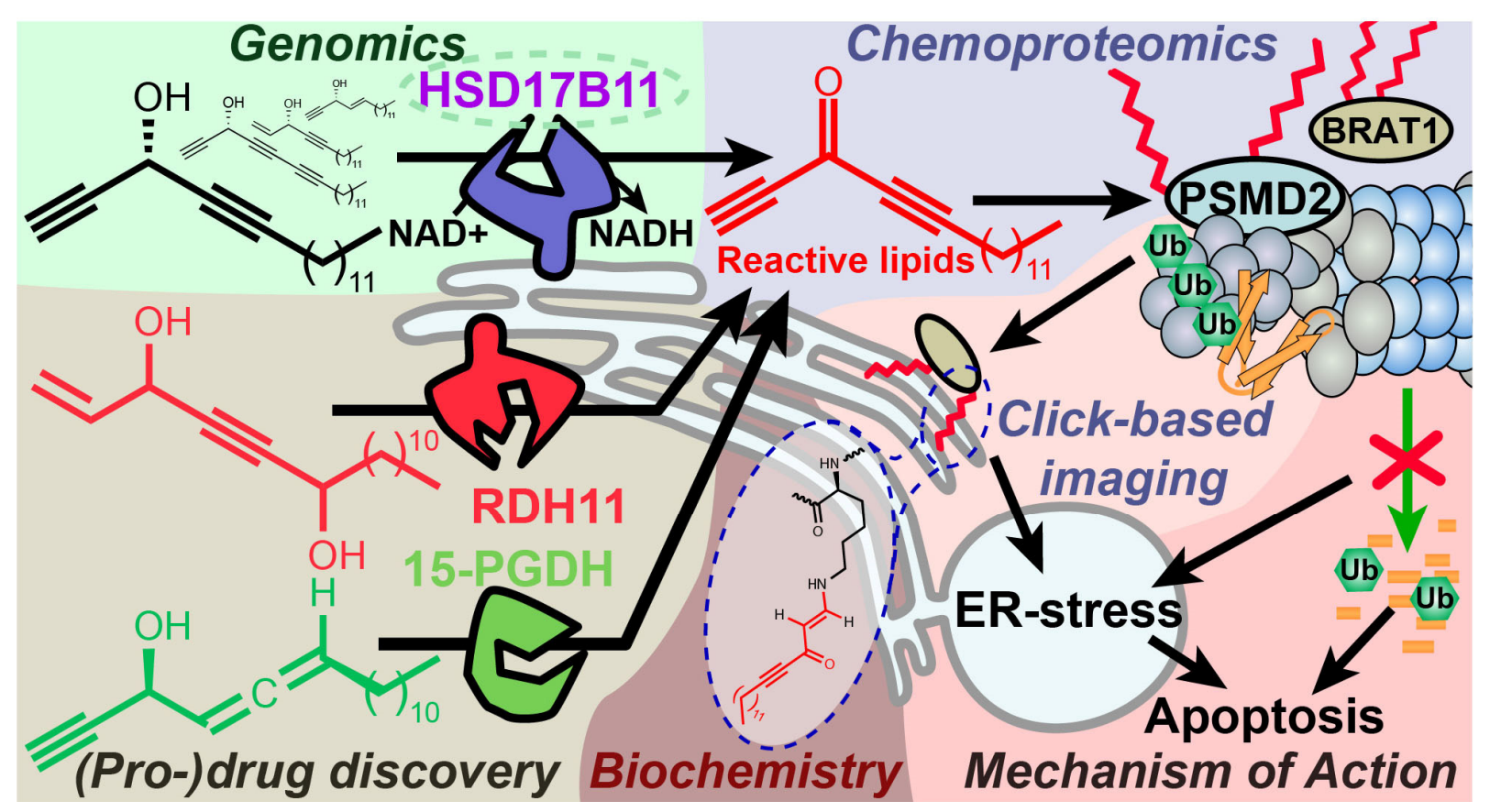

